\title{
Characterization and In Vitro evaluation of a novel coated nanocomposite porous 3D scaffold for bone repair
}

\author{
S.M. Ibrahim ${ }^{1, a}$, S.K. Mahmood ${ }^{2, b}$, I.S. Razak ${ }^{2}$ L.M. Yusof ${ }^{1}$, Z.K. Mahmood ${ }^{3}$, \\ F.I. Gimba ${ }^{5}$ and M.Z. Zakaria ${ }^{2,4}$ \\ ${ }^{1}$ Department of Companion Animal Medicine and Surgery, ${ }^{2}$ Department of Veterinary Preclinical Sciences, ${ }^{3}$ Department of \\ Veterinary clinical Studies, Faculty of Veterinary Medicine, ${ }^{4}$ Laboratory of Molecular Biomedicine, Institute of Biosciences, \\ Universiti Putra Malaysia (UPM), 43400, Serdang, Selangor Darul Ehsan, Malaysia, \\ ${ }^{5}$ Avian Influenza Control Project, Animal Components, Taraba State Ministry of Agriculture and Natural Resources Jalingo, \\ Taraba, Nigeria \\ ${ }^{a}$ Department of Surgery and Theriogenology, ${ }^{b}$ Department of Anatomy, \\ College of Veterinary Medicine, University of Mosul, Mosul, Iraq
}

(Received May 28, 2018; Accepted October 2, 2018)

\begin{abstract}
The aim of this study is to tissue engineer a 3D scaffold that can be used for load bearing segmental bone defects (SBDs) repair. Three different scaffolds were fabricated using cockle shell-derived $\mathrm{CaCO}_{3}$ aragonite nanoparticles (CCAN), gelatin,

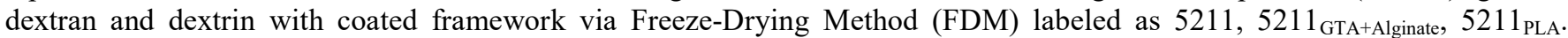
Scaffolds were assessed using Scanning Electron Microscopy (SEM). The cytocompatibility of the organized scaffolds was assessed using cells multiplication and alkaline phosphatase (ALP) concentration via In Vitro cell culture using human Fetal OsteoBlast cells line (hFOB). The results showed a substantial difference in ALP concentrations between the cultures of different scaffolds leachable medium during the study period. The biological evaluation also showed that three scaffolds did enhanced the osteoblast proliferation rate and improved the osteoblast function as demonstrated by the significant increase in ALP concentration. Engineering analyses showed that scaffolds possessed 3D interconnected homogenous porous structure with a porosity ranging $6 \%-49 \%$, pore sizes ranging 8-345 $\mu \mathrm{m}$, mechanical strength ranging 20-65 MPa, young's modulus ranging 166-296 MPa and enzymatic degradation rate between 16\%-38\% within 2-10 weeks. The in vitro evaluation revealed

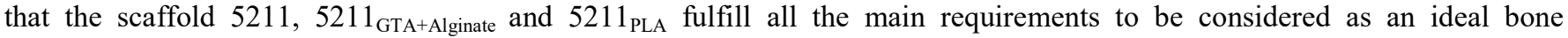
replacement.
\end{abstract}

Keywords: Aragonite, bionanocomposite, 3D porous scaffold, $\mathrm{hFOB}$, Bone repair Available online at http://www.vetmedmosul.com

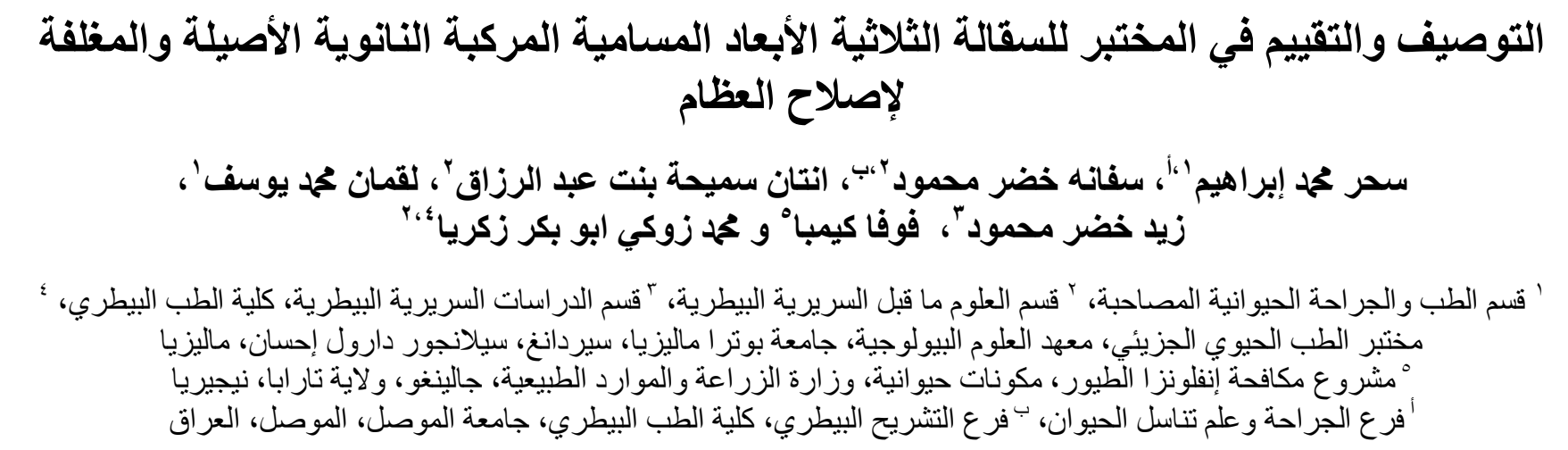

هدفت هذه الدراسة هو تصميم سقالة نسيجية ثلاثية الأبعاد والتي يمكن استخدامها لإصلاح عيوب قطعية الحاملة للعظام.

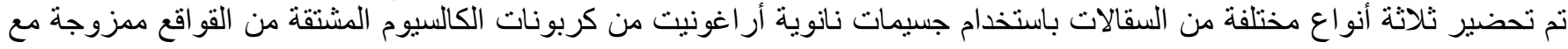




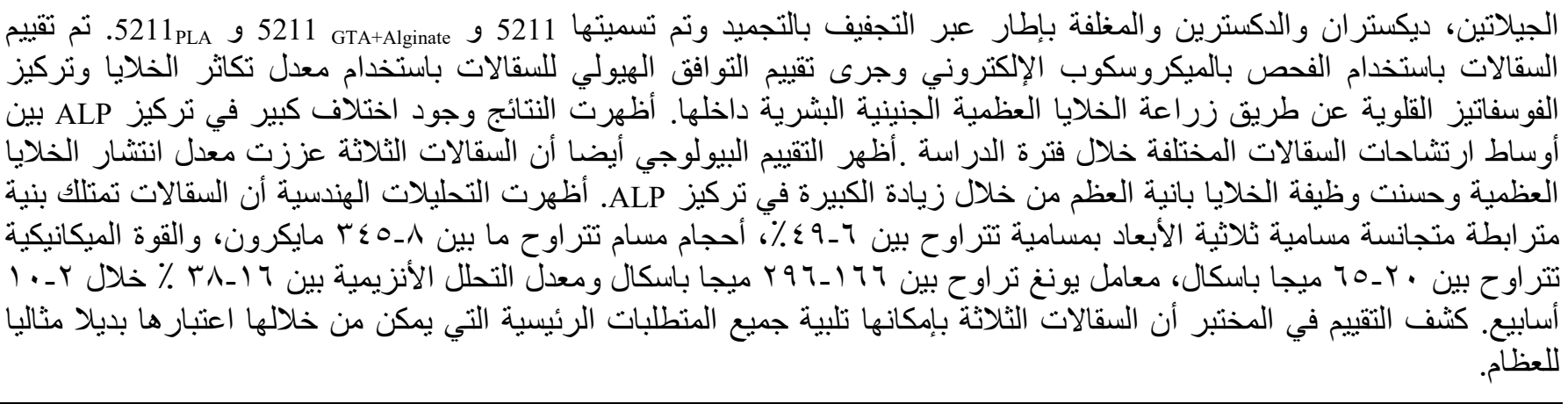

\section{Introduction}

The thoughts of restoring a damaged body have been in existence since the start of humankind with early history manifesting them as myths and magic. Tissue engineering in biomedical research is concerned with repairing damaged tissues and restoring their functions (1-7). The human bone represents one of the most important organs of the human body. These rigid organs play an essential role in providing the needed support, protection and movement. Over a century, the process of bone grafting has been utilized by orthopedic surgeons due to the constant need for bone replacement. Presently the alternatives for treating injuries are inadequate as they depend on allografts, autografts, and biomimetic or variety of synthetic materials and strategies (8). Base on (9), definition tissue engineering is known as a multidisciplinary area that uses the values of engineering and the life sciences in the direction of the improvement of biological alternatives which maintains, reestablish or progressive function of tissue. The replacements are commonly branded as "scaffolds". Scaffolds serve a significant part in the field of tissue engineering in terms of providing the required $3 \mathrm{D}$ architecture that facilitates the regeneration of new tissues. The $3 \mathrm{D}$ scaffold design is the ideal structure that has sufficient porosity, interconnectivity and suitable pore size that permits proper transportation and adequate migration of cells, nutrients, signal molecules, metabolites, innervations and proper vascularization of the newly grown tissues (10-11). A number of polymers are normally used in bone scaffolds, including collagen, gelatin, alginate, chitosan, polylactic acid (PLA), polyglycolic acid (PGA) and polycaprolactone (PCL). There exist several developed approaches for manufacturing scaffolds. Numerous recognized procedures comprise of gas foaming, solvent casting, phase separation, textiles and manufacturing freeform are accepted techniques.

The cockle shell consists of about $96 \% \mathrm{CaCO}_{3}$ whilst other components include organic substances and other oxides like $\mathrm{SiO}_{2}, \mathrm{MgO}$ and $\mathrm{SO}_{3}$. Based on the previous studies, it was recommended that the cockle shell-derived
$\mathrm{CaCO}_{3}$ powder $(\mathrm{CCP})$ can be used as good optional biomaterial for bone replacement in organization of bone defects (12-17). In past 10 years, CCP was used to fabricate a novel porous scaffold. Aragonite is synthesized through the combination of calcium and carbonate salts as the primary substances. This type of production needs the occurrence of all the types of organic additives or many extra double ions (18).

Practically, the cockle shell permeable forms are used as bone scaffolds to ascertain an upgrade bone ingrowth and osseointegration. Though, the fragility and low strength narrow their widespread applications in hard tissue implantations to be used efficiently in weight bearing parts, the mechanical properties of the CCAN porous body have to be enhanced $(19,20)$. Among the most significant property and advantage of scaffold tissue engineering is its biological response; the achievement of bone tissue engineering implantations depends largely on using suitable biological reaction in vivo. The capability of the scaffold to sustain the cells attachment, growth and the possible differentiation of cells in the appropriate tissue depends on the pore interconnectivity, chemistry, surface properties and permeability of the scaffold. Thus, tissue engineering of bone, osteoblasts and a suitable matrix could be used to restore continuity of the skeleton and normality of bone (21-22).

The human Fetal Osteoblast cells (hFOB 1.19 (ATCC ${ }^{\circledR}$ CRL-11372)) is capable to distinguish into matured osteoblasts expressing the usual osteoblast phenotype. hFOB cells are a frequently used cell line that represents the human osteoblast cells. the hFOB cells are becoming well established in the field of bone tissue culture studies due to their ability to produce a bone specific alkaline phosphatase (ALP) response and osteocalcin in response towards an inducing agent as an indicator of osteogenic differentiation in addition to exhibiting many other bones forming cell traits and characteristics that makes them an excellent choice for in vitro studies (23-25).

The production and assessment of the novel coated nanocomposite 3D scaffolds prepared by a mixture of aragonite $\mathrm{CaCO}_{3}$ nanoparticles, gelatin, dextran and dextrin 
as a potential bone matrix for tissue engineering have not been done, thus the purpose of this research was to produce and assess the morphological, physicochemical and mechanical properties of the novel coated nanocomposite 3D scaffolds as a potential bone matrix for tissue engineering and determining the biological properties of them by measuring and evaluating the effects of materials used (CCAN, gelatin, dextrin, dextran, GTA, alginate and PLA) on cell behavior.

\section{Materials and methods}

\section{Cockle shell-derived $\mathrm{CaCO}_{3}$ aragonite nanoparticles powder preparation}

The CCP was prepared using the technique described by (26). However, some modifications were made to obtain the best results of micro and nanoparticles size. The shell was dried in oven (Memmert, UM 500, Germany) at $50{ }^{\circ} \mathrm{C}$ for 5-7 days, ground using stainless steel blender (Good and Well $^{\circledR}$, Taiwan) and sieved through $75 \mu \mathrm{m}$ sieve (Endecotts Ltd, London, England). The micron sized powder was additionally desiccated in the oven (Memmert, UM 500, and Germany) at $50^{\circ} \mathrm{C}$ for 5 days and kept in air tight polyethylene plastic bag (JP Packaging) until used. The obtained micron sized powder $75 \mu \mathrm{m}$ was transformed into nanoparticles using a mechano-chemical technique in the occurrence of surfactant BS-12 (dodecyl dimethyl bataine) that was achieved from Sigma-Aldrich (Steinheim, Germany) and Ball mill ( $\left.\mathrm{Wisd}^{\circledR}\right)$. Briefly, mechanical stirring of the 2 grams of $75 \mu \mathrm{m}$ powder with the $50 \mathrm{ml}$ deionized water (DW) (HPLC-grade of resistance $>18 \mathrm{M} \Omega$ obtained from a MilliRO6 plus Milli-Q-Water System (Organex) and $0.5 \mathrm{ml}$ of surfactant BS-12 at $1000 \mathrm{rpm}$ at room temperature for 90 minutes through the use of the heating homogenize stirrer machine (Wise Stir ${ }^{\circledR}$ Heating Multiple Stirring). The resultant slurry was then filtered using filter paper size $12.5 \mathrm{~cm}$ (Filtres Fioroni, China) and dried at $80^{\circ} \mathrm{C}$ overnight then stored at $50^{\circ} \mathrm{C}$ in a sterile container prior to use (27). The obtained nanosized powder was mechanically rolling again using roll mill machine (Wisd ${ }^{\mathbb{B}}$ Ball Mill, Korea) for 7 days.

\section{Development of the scaffolds}

Three materials; gelatin, dextran and dextrin, were mixed with CCAN powder to formulate the three scaffolds according to (27) method and conclusion: Scaffold 5211 (S1): Cockle shell-derived $\mathrm{CaCO}_{3}$ aragonite nanoparticles (CCAN) $50 \%$, gelatin $25 \%$, dextran $10 \%$ and dextrin $15 \%$. Scaffold $5211_{\text {GTA }}$ Alginate $(\mathrm{S} 2)$ : CCAN 50\%, gelatin $25 \%$, dextran $10 \%$ and dextrin $15 \%$, soaked in crosslinking GTA and coated using Alginate. Scaffold 5211 $1_{\text {PLA }}$ (S3): CCAN $50 \%$, gelatin $25 \%$, dextran $10 \%$ and dextrin $15 \%$, coated using PLA.

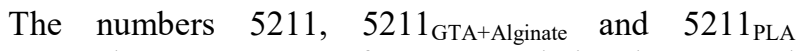
represent the percentages of CCAN, gelatin, dextran and dextrin respectively with and without cross linked and coated framework, and the scaffolds were prepared by deep freezing method. Combination of the three materials (gelatin, dextran, dextrin) was first dissolved in hot deionized water at $70^{\circ} \mathrm{C}$ for 90 minutes using the heating homogenize stirrer machine (Wise Stir ${ }^{\circledR}$ Heating Multiple Stirring) at $400 \mathrm{rpm}$ and CCAN powder (coated and noncoated) was added to the mixture and stirred until a uniformly smooth slurry was achieved. The combination was poured into a cylindrical mold of aluminum foil $4 \mathrm{~cm}$ height $\times 1 \mathrm{~cm}$ diameter, allowed to set slightly before being transferred to $-20{ }^{\circ} \mathrm{C}$ for 24 hours then transferred to the deep freezer at $-80^{\circ} \mathrm{C}$ and the scaffolds was later freeze dried in a freeze drier (LABCONCO Freezon6 USA) for lyophilization till it is completely dried for 4 days at $-50^{\circ} \mathrm{C}$, and later kept in a sterile container before future use.

S2 was soaked in Glutaraldehyde (GTA) $0.25 \%$ the most popular crosslinking treatments for biological tissues for 30 minutes and later coated using polymer Alginate 5\% before being transferred to $-20^{\circ} \mathrm{C}$ for 24 hours then transferred to the deep freezer at $-80^{\circ} \mathrm{C}$ and the scaffolds was later freeze dried in a freeze drier (LABCONCO Freezon6 USA) for lyophilization till it is completely dried for 4 days at $-50^{\circ} \mathrm{C}$. While S3 was coated using polylactic acid (PLA) 5\% solution that was achieved from Sigma-Aldrich (Steinheim, Germany) in room temperature.

\section{Scaffold characterization}

Scanning electron microscopy (SEM)

Examination of prepared scaffolds was done by Scanning Electron Microscopy (JEOL JSM 6400 SEM ATTACHED WITH EDX, Germany) according to $(19,20)$ methods. Cutting of the scaffolds into smaller circular and longitudinal sections were done and sent to the Electron Microscopy Unit, Institute of Bioscience, Universiti Putra Malaysia (UPM) for SEM analysis. Microstructural characterization and average pore diameter of measurement based on 300 measurements that was taken from six replicates.

\section{Porosity evaluation}

Porosity of the organized scaffolds was examined via fluid dislocation using ethanol; this method was adopted from (28). The scaffolds where been cuts into reduced circular discs, $1 \mathrm{~cm}$ in thickness and $1 \mathrm{~cm}$ width. The primary dry weight $\left(\mathrm{W}_{\mathrm{d}}\right)$, the radius $(\mathrm{R})$ and the thickness (T) of 6 samples per scaffold were calculated preceding immersions. Samples were later dipped in $20 \mathrm{ml}$ ethanol alcohol and later preserved with an evacuationrepressuriztion system till there were no bubble coming out of the samples and left in ethanol for 48 hours, to allow thorough saturation, and were weighed and recorded as 
$\left(\mathrm{W}_{\mathrm{w}}\right)$. Scaffold porosity was determined using the formula below.

Porosity Percentage $=\left(\mathrm{W}_{\mathrm{w}}-\mathrm{W}_{\mathrm{d}}\right) /$ Pet $\mathrm{x} \pi \mathrm{R}^{2} \mathrm{Tx} 100 \%$

While $\left(\mathrm{P}_{\mathrm{et}}\right)$ represent the density of ethanol.

\section{Swelling evaluation}

Swelling work was conducted following (29) method. This measured the absorption/diffusion of the nutrients to the scaffolds which is important for cell capability and growth. The swelling test determined the proportion of the uptake of the medium by every scaffold. Six samples of each type of the fabricated scaffolds were used in this study; the weights of each sample were measured earlier and after phosphate buffer solution soaking (PBS) $\mathrm{pH} 7.4$ for 10 minutes. The differences amongst the weight of wet and dry scaffolds denote the amount of PBS solution from which the proportion of medium uptake was determined using the below formula:

\section{Percentage of Medium Uptake $=\left(\mathrm{W}_{2}-\mathrm{W}_{1}\right) / \mathrm{W}_{1} \times 100 \%$}

Where, $\left(\mathrm{W}_{1}\right)$ is the original sample weight prior to immersion (dry) and $\left(\mathrm{W}_{2}\right)$ is the sample weight after immersion (wet). The above process was repeated after drying the same scaffolds samples for another 10 minutes. The finest sample was recognized based on the comparison between the scaffolds for the first and the second percentage of PBS absorption.

\section{Water absorption evaluation}

Water absorption study was carried out using six samples of each type of scaffold. The weights of samples were measured before and after immersion in deionized water for 10 minutes. The variances amongst the weight of wet and dry samples denote the amount of absorbed water from which the proportion of absorbed water was determined using the formula below:

Water Absorption Percentage $=\left(\mathrm{W}_{2}-\mathrm{W}_{1}\right) / \mathrm{W}_{1} \times 100 \%$

Where, $\left(\mathrm{W}_{1}\right)$ is the early sample weight before soaking (dry), and $\left(\mathrm{W}_{2}\right)$ is the sample weight after soaking (wet). The above method was repeated after drying the scaffolds for another 10 minutes.

\section{Degradation test}

3D nanocomposite scaffolds degradation was investigated in PBS solution $\mathrm{pH} 7.4$ using two approaches. The first approach enzymatic method entailed the study of the degradation rate using lysozyme, in adoption of (30) method. Six samples measuring $1 \mathrm{~cm}$ in diameter and $1 \mathrm{~cm}$ in thickness each were tested from each scaffold type. The samples were immersed in PBS solution comprising 10,000 $\mathrm{U} / \mathrm{ml}$ lysozyme at $37{ }^{\circ} \mathrm{C}$ for 2 weeks. The liquids were changed each 3 days to guarantee continuous enzyme activity. The early weights of each sample of the scaffolds were recorded as $\mathrm{W}_{0}$. The samples were removed after 2 weeks and freeze dried for 4 days at $-50{ }^{\circ} \mathrm{C}$. The samples were later weighed and the dry weight recorded as $\left(\mathrm{W}_{1}\right)$. The degradation percentage was later determined using the formula below:

Degradation Percentage $=\left(\mathrm{W}_{0}-\mathrm{W}_{1}\right) / \mathrm{W}_{0} \times 100 \%$

For the second semi-quantitative method, six samples measuring $1 \mathrm{~cm}$ in diameter and $1 \mathrm{~cm}$ in thickness each were collected from each scaffold type for the 2 weeks semiquantitative experiment. Photographs were obtained at fixed time intervals to show the physical changes of the degrading scaffolds. During the degradation of the samples, the $\mathrm{pH}$ changes were also concurrently measured at changeable intervals.

For third semi-quantitative method, this study adopted a direct visual examination method (by naked eye) to assess the degradation rate. At different periods of time, comparison of the scaffold condition by monitoring the changes in the scaffold dimensions soaked in special environment. Six samples were collected from every scaffold measuring $1 \mathrm{~cm}$ in width and $1 \mathrm{~cm}$ in thickness each were used for these 2 weeks semi-quantitative experiment. The samples were immersed in deionized water. The information provided by the degradation in PBS solution pH 7.4 using the two approaches and through the direct visual observation method was acceptable to judge the differentiation in degradation rates of different types of scaffolds with different manufactured components.

\section{Mechanical strength evaluations}

The compressive mechanical ability and modulus of scaffolds were tried through the use of an Instron 3365 mechanical tester (Instron 3365, $10 \mathrm{KN}$ load-cells, Canton, MA, USA) with $10 \mathrm{kN}$ load cells (31). Six samples were collected from every scaffold which was made as circular discs of $1 \mathrm{~cm}$ in width and $1 \mathrm{~cm}$ breadth. The speed of a crosshead which used was $0.4 \mathrm{~mm} / \mathrm{min}$ and the load was applied until the samples were compacted to about $100 \%$ of its early height.

\section{Fourier Transform InfraRed (FTIR) analysis}

To find out the chemical functions of the 3D nanocomposite scaffolds, the spectroscopic technique utilizing a Fourier Transform InfraRed (FTIR) spectrophotometer (Perkin Elmer) was used in the ranges of $400 \mathrm{~cm}^{-1}$ to $4000 \mathrm{~cm}^{-1} .1-2$ grams of samples was prepared and used through UATR procedures.

\section{Powder X-Ray Diffraction (PXRD) analysis}

1-2 grams of samples of each scaffold type were ground and used for this analysis. The $\mathrm{x}$-ray powder diffraction analysis is a sensitive test used for the recognition of 
crystalline phases of inorganic compounds (Shimadzu XRD-6000 powder diffractometer using $\mathrm{CuK} \alpha$ $(\lambda=1.540562 \AA)$ at $40 \mathrm{kV}$ and $30 \mathrm{~mA})(32)$. The scaffolds powders were sent to the Material Science Laboratory, Department of Chemistry, Faculty of Science (FOS), Universiti Putra Malaysia for PXRD analysis. The X-ray powder diffractometer is a very useful analytical method that is based on the principle that $\mathrm{x}$-rays of wavelength that is known passes through a sample to be recognized in identifying the crystal configuration. The crystals lattice diffract the wave nature of the x-rays giving an exceptional shape of peaks of 'reflections' at different viewpoints and of diverse strength, as light can be deflected by means of a rough suitably spaced shapes. According to Bragg principle, the deflected rays from atoms in succeeding planes cancel except they are in phase. Preparation of samples for PXRD entailed packing about 2 grams of scaffold powder to the holder through the use of a standard back fill technique appropriately secure adequately for it not to drop out throughout the $90 \varnothing$ tilt test. The analysis entailed performing wide-angle $\mathrm{x}$-ray diffraction to differentiate the nature of amorphous and crystalline components of the samples at room temperature. The diffraction form was collected at a rate of scanning 0.02 degrees per second in $2 \theta$ at a range of $20^{\circ}$ to $60^{\circ}$ at $37^{\circ} \mathrm{C}$. The PXRD using Scherrer's formula to equate with the value gotten from TEM analysis results. The crystallite sizes Dv is an easy technique that openly distinguishes between strain induced and size induced peak extending through seeing the peak length as a function of $2 \theta$ (33).

\section{Differential Scanning Calorimetry (DSC) analysis}

Differential Scanning Calorimetry (DSC) was performed on scaffold samples to examine their thermal characteristics. The thermal change of the scaffolds powder developed from different combinations was examined through the use of differential scanning calorimeter (METTLER TOLEDO DSC822e Switzerland). About 1-2 grams of samples of each scaffold were grounded, prepared and used for this analysis. The sample powders were scanned at room temperature. The samples were heated up to $250^{\circ} \mathrm{C}$ at the rate of $10^{\circ} \mathrm{C} /$ minutes, held isothermally for five minutes and cooled again to $25^{\circ} \mathrm{C}$ during each cycle. During the first cycle, the heat of the melting temperature, (Tm), was recorded in order to find out the crystallinity. The minimum of the melting peak was defined of melting temperature. During the second cycle, the glass transition temperature $(\mathrm{Tg})$ was calculated as the inflection point of the glass transition.

\section{In vitro culture}

hFOB cells 1.19 acquired from American Type Culture

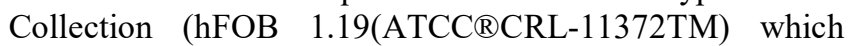
were full-grown in the cell culture material in an atmosphere that is controlled using the manufacturer's guide. Cells from each vial were seeded into a T25 culture flask which contains Ham's F12 Dulbecco's Modified Eagle Medium with $2.5 \mathrm{mMl}$-glutamine (without phenol red) (DMEM Ham's F\&\#8208; 12 with L \& \# 8208; Gin, sodium Pyruvate and HEPES, deprived of phenol Red) supplemented with 10\% Fetal Bovine Serum (FBS: JRS1243640, USA) and $1 \%$ Geneticin Solution (G418, nacalai tesque, Japan) at $34^{\circ} \mathrm{C}$ temperature and $5 \% \mathrm{CO}_{2}$ (following the manufacturer's guide). The solution was replaced with a new solution after each 2-3 days, the cells were consistently divided into 1:2 every $3-4$ days at $80 \%$ convergence. The cells were separated by the used of trypsin/EDTA (0.25\%Trypsin/1mM- EDTA Solution, nacalai tesque, Japan), concentrated through centrifugation process for 5 minutes at $1200 \mathrm{rpm}$ and resuspended in fresh medium. Cells in the fourth and fifth passage were used for seeding purposes in the experiments.

\section{Preparation of scaffolds extracts}

The scaffolds were initially cut into cylindrical blocks shapes measuring $1 \mathrm{~cm}$ in diameter $\mathrm{x} 1 \mathrm{~cm}$ height. The precut scaffolds were stored in scotch bottles and sterilized by Ultraviolet light (UV) irradiation for about 5 hours prior to use in the experiments. Extracts from three scaffolds developed in this study preparation was done in accordance to (30) method which was for MTT assay purpose as well as ALP analysis. Sterilized scaffolds prepared earlier were nurtured in $20 \mathrm{ml}$ complete culture media for 24 hours at a temperature of $34^{\circ} \mathrm{C}$ to achieve the scaffold leachable. The leachable from every scaffold were later collected into separately labeled falcon tubes which are sterile and were kept for further use at $4^{\circ} \mathrm{C}$.

\section{MTT (3-(4, 5-dimethyl-2-thiazolyl)-2, 5-}

\section{diphynyltetrazolium bromide) colorimetric assay}

The assay of MTT was done in accordance to (30) methods. Six well plate was used to seed the hFOB cells at a density of $1 \times 10^{4}$ cells/well. Cells were nurtured for 24 hours in normal culturing settings this is to permit primary attachments. Medium were removed from every single well after 24 hours and were exchanged with medium that contains the leachable extracts of scaffolds and which was again incubated for 24, 48 and 72 hours, and continue the incubation for 5, 7 and 14 days for three scaffolds. After the period of incubation, the medium with scaffold extracts were taken in every well and substituted with new medium which contains $10 \%$ of MTT solution ((3-(4, 5-dimethyl-2thiazolyl)-2, 5-diphynyltetrazolium bromide, nacalai tesque, Japan). The cells were later incubated for 4 additional hours at $34 \mathrm{C}$ this is done to achieve the standard MTT assay. Medium were removed after 4 hours and $0.8 \mathrm{ml}$ dimethyl sulfoxide (DMSO, Mediatech, Inc.; A corning Subsidiary, Manassas, VA 20109, USA) was added to conclude the 
reaction as a solubilization buffer to all the wells for formazan crystals dissolution. The lysate absorbance reading was taking at a $495 \mathrm{~nm}$ wavelength using ELISA reader (TECAN-infinite M200 PRO) and the result was given as absorbance obtained from every well and compared with the control which was cultured with standard medium of culture.

\section{Alkaline Phosphatase (ALP) activity}

ALP activity was resolute in culture medium according to the methods of (34). The activity of enzyme was determine using a pNPP (p-nitrophenyl phosphate) assay. The assay is sensitive and can reproduce technique that is preferably suitable for determining ALP actions by incubating $0.8 \mathrm{ml}$ of collected medium samples with $0.8 \mathrm{ml}$ of $0.5 \mathrm{ml}$ of Alkaline Buffer Solution (Sigma 221) and 0.5 $\mathrm{ml}$ of Stock Substrate Solution (40 mg p-nitrophenyl phosphate disodium (Sigma 104) diluted in $10 \mathrm{ml}$ of sterilized purified $\mathrm{H}_{2} \mathrm{O}$. The solution was incubated at $34^{\circ} \mathrm{C}$ for 1 hour in a 6 well plate to determine the ALP activity in regards to the formation of p-nitrophenol. In this technique, the ALP changes the hydrolysis of $\rho$-Nitrophenyl phosphate (pNPP) to $\rho$-Nitrophenol. pNPP which is neutral in color (colorless) but $\rho$-Nitrophenol has a high absorbance at 405 $\mathrm{nm}$. The increased level of absorbance at $405 \mathrm{~nm}$ is relative to the action of the enzyme. ELISA (TECAN-infinite M200 PRO) was used to read the absorbance of the solution and was conveyed as absorbance reading from every well and compared with the control which was cultured with standard medium of culture.

\section{Statistical analysis}

First of all, the quantifiable outcomes were evaluated using Explore for Normality of data then One-Way Analysis of Variance (ANOVA) and Kruskal-Wallis Test. The outcomes were shown as Mean \pm Standard Error (SE). Post Hoc Test were calculated for significant values $(\mathrm{P}<0.05)$ through the use of Tukey's Multiple Comparison Test. All descriptive and inferential statistical analyses was conducted using Excel version 2013 and SPSS version 21.0 and 22.0.

\section{Results}

\section{Characterization of cockle shell-derived $\mathrm{CaCO}_{3}$ aragonite nanoparticles}

The TEM for nanoparticles revealed aragonite calcium carbonate nanoparticles with range size of 15.94-55.21 \pm 6 $\mathrm{nm}$ (Figure 1). There was no change in the elemental configurations of the gotten CCAN post synthesis using of BS-12 and roll mill. This reflects the surfactant role of BS12 and roll milling in the break of the larger sized aragonite rods into smaller spherical ones.

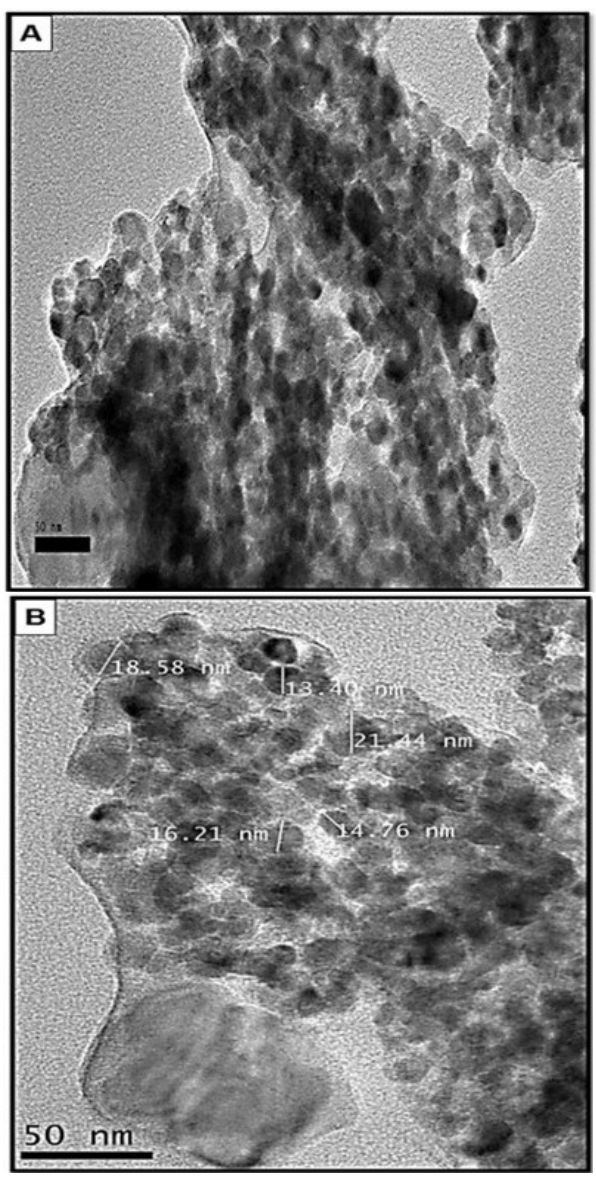

Figure 1: Transmission electron micrographs show the shape and the size of cockle shell-derived $\mathrm{CaCO}_{3}$ aragonite nanoparticles using roller mill, (A and $\mathrm{B}$ ), $\mathrm{Bar}=50 \mathrm{~nm}$.

\section{Characterization of scaffolds}

Figure 2 shows the non-coated and coated developed scaffolds in different compositions. The scaffolds formed were found to be stiff in structure. The whiteness of the scaffolds varies based on the cross linked and coated copolymers. The scaffolds were also found to be hard enough to bear up the physical manual compression in dry state especially those coated with alginate and PLA, which allows it to be simply handled and cut into desired sizes for further studies.

\section{Scanning Electron Microscopy (SEM)}

The scaffolds that were prepared by freeze dry method gave rise to structures that consisted of open networks of pores, with pore sizes that ranged from 8.1 to $345 \mu \mathrm{m}$ (Table 1). The pores revealed a high level of interconnection, which is crucial for cell seeding and development. With this method it was promising to control the porosity ratio and the pores size. SEM analysis showed excellent micro pores structure. However, the scaffolds S2 
and S1 showed an extremely wide pore structures ranging from 8.1-252 $\mu \mathrm{m}$ and 8.97-337 $\mu \mathrm{m}$ respectively (Figure 3 and Table 1). The pores were round in structure with diameters ranging between 64.45-73.72 $\mu \mathrm{m}$. However, the group of scaffolds showed higher calcium carbonate crystallites deposited on the surface of the gelatin, dextran and dextrin polymer. Noteworthy to mention that there was a negative relation between the pore size and using coated framework and the type of coating copolymer. No significant differences were observed between the scaffolds for pores diameters at $(\mathrm{P}>0.05)$.

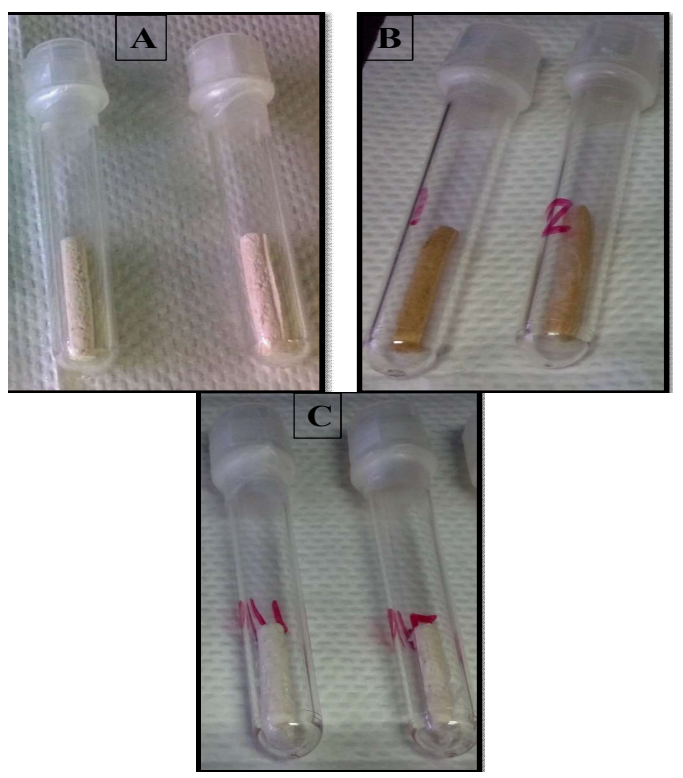

Figure 2: Photographs show scaffolds S1 (A), S2 (B) and S3 (C) after drying in the freeze dryer machine, which ready to be used.

Table 1: Summary of pores diameters of each scaffold $($ Mean \pm SE)

\begin{tabular}{ccc}
\hline Scaffold & Range of pores diameter & Mean of pores diameter \\
\hline S1 & $8.97-337 \mu \mathrm{m}$ & $71.27 \mu \mathrm{m} \pm 4$ \\
S2 & $8.1-252 \mu \mathrm{m}$ & $64.45 \mu \mathrm{m} \pm 6$ \\
S3 & $9.25-345 \mu \mathrm{m}$ & $73.72 \mu \mathrm{m} \pm 6$ \\
\hline
\end{tabular}

\section{Porosity evaluation}

Scaffolds from different compositions showed significant differences at $(\mathrm{P}<0.05)$ in the porosity percentage between $6.4 \%-48.9 \%$ (Figure 4 ). The results showed that the lower percentage of porosity is depended on the type of copolymer that used in coated framework.

\section{Swelling evaluation}

Figure 5 shows the percentage of medium uptake of each scaffold at a given period obtained by manipulative changes in scaffold weight. S3 showed the lowest PBS solution absorbing ability at $26.99 \pm 1 \%$ and $23.15 \pm 1 \%$ in the first and second 10 minutes. The PBS solution ability of the three scaffolds were found to vary between $27 \%$ to $46 \%$ for first 10 minutes and between $23 \%-29 \%$ for second 10 minutes with significant differences between the scaffolds for first and second 10 minutes at $(\mathrm{P}<0.05)$.

\section{Water absorption evaluation}

Figure 5 shows the outcome of water absorption test for different composition of scaffolds. After the first 10 minutes, no substantial differences were witnessed between the scaffolds at $(\mathrm{P}>0.05)$. The second 10 minutes of immersion was done after the scaffolds were left to dry. The percentage of water absorption had dropped in all scaffolds especially S3. All types of scaffolds showed significant difference between the scaffolds for the second 10 minutes at $(\mathrm{P}<0.05)$.

\section{Degradation test}

The degradation study of the scaffolds was carried out using an enzymatic way as well as two semi-quantitative methods for a time period of 2, 4 and 10 weeks. The results show that $\mathrm{S} 3$ showed higher degradation rate at $38 \%$ and $\mathrm{S} 1$ showed lower degradation rate at $16 \%$ compared to other scaffolds (Figure 5). The degradation rate of the scaffolds was different from one to other, S1 showed lower degradation at $16 \%$ at day 10 of test, while S3 and S2 degraded at $38 \%$ at 4 weeks and $27 \%$ at 10 weeks respectively (Figure 5 and Table 2). Coated scaffolds showed moderate degradation rate within 4-10 weeks (Figure 5 and Table 2). Moreover, there was significant differences in the degradation percentage of all the scaffolds studied at $(\mathrm{P}<0.05)$. The results from scaffold degradation periods showed different model of degradation as observed throughout the enzymatic degradation studies, coated scaffolds showed slow degradation approach with very small surface defects and very little fissure within 4-10 weeks.

\section{pH Changes during degradation study}

Tables 3 and 4 show the changes in $\mathrm{pH}$ during the experimental period. There were significant changes in the $\mathrm{pH}$ within the scaffold groups, in addition significant changes between groups were observed after 24, 288 and 336 hours in PBS; and after 24, 168, 288 and 336 hours in Lysozyme at $(\mathrm{P}<0.05)$. No significant changes were seen between groups after 72 and 168 hours in PBS; and after 72 hours in Lysozyme at $(\mathrm{P}>0.05)$. There was a substantial rise in the $\mathrm{pH}$ in $\mathrm{S} 1$ compared to other scaffolds at the end of the study period at $(\mathrm{P}<0.05)$. An increased $\mathrm{pH}$ to a basic condition was observable within most of the scaffolds with a maximum $\mathrm{pH}$ of 9.09 and 8.89 in $\mathrm{S} 1$ in PBS and Lysozyme correspondingly. 


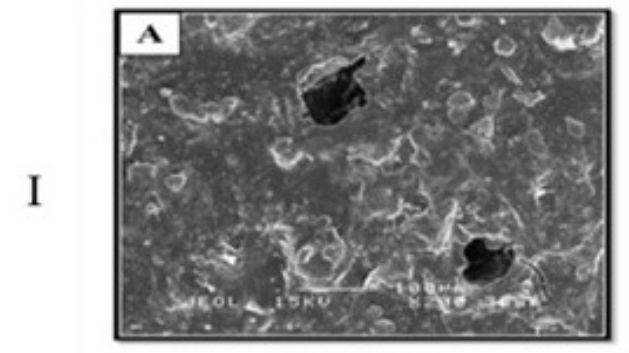

Seafrold 5211

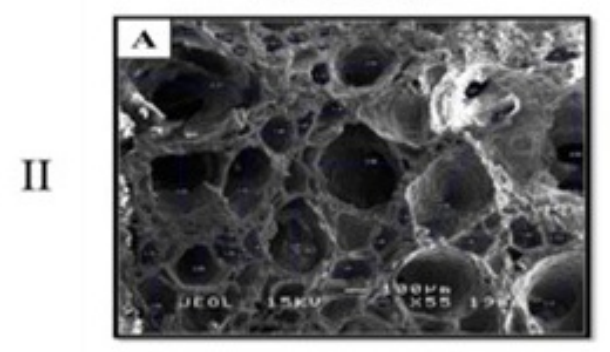

Scaffold 5211

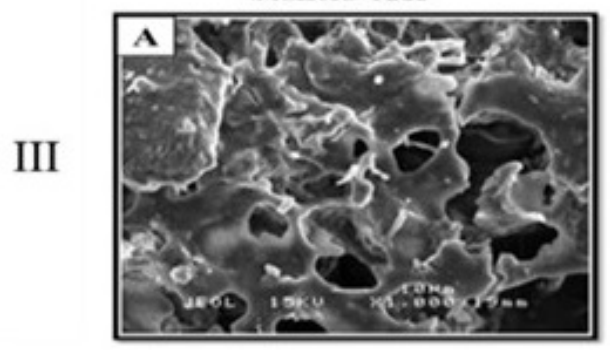

Scaffold 5211

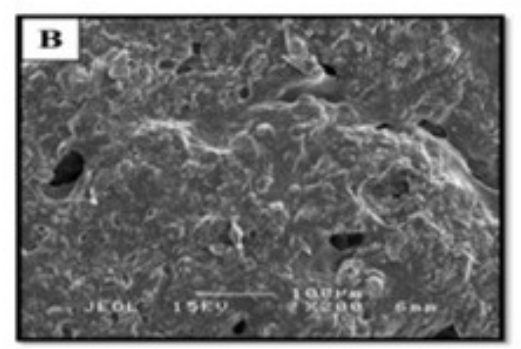

Seaffold S2110rAvalyante

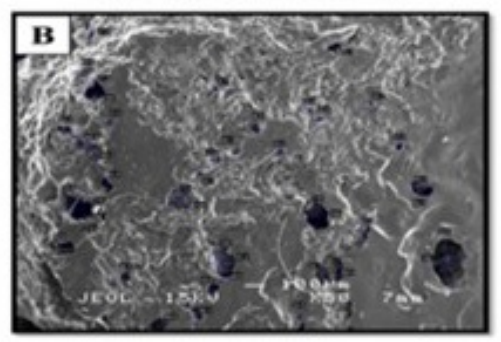

Scaffold 5211 erantemen

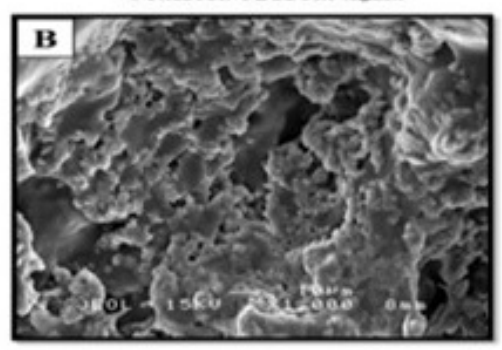

Scaffold 5211 exarahean

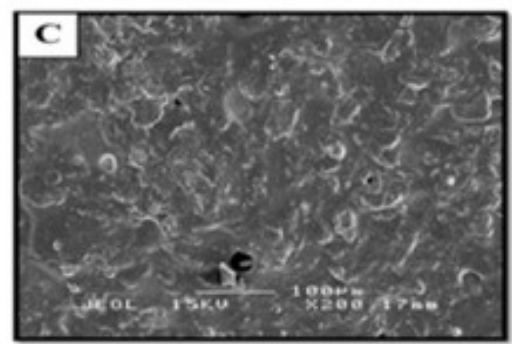

Seaffold $5211 \mathrm{mu}$

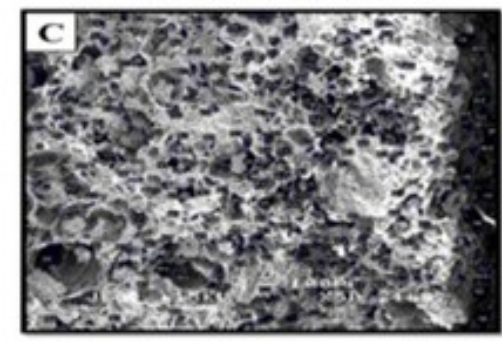

Scaffold $5211 \mathrm{~m}$.

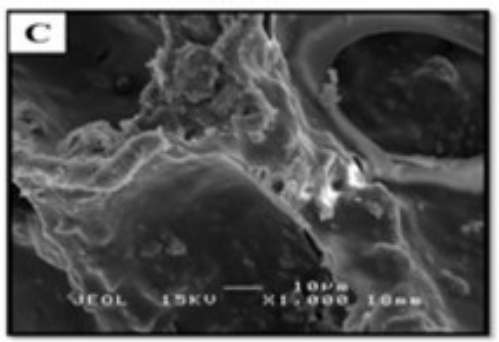

Seaffold 5211m

Figure 3: Scanning electron micrographs show the surface structure (I, X200), the internal structure and pores diameters (II, X50) and the presences of $\mathrm{CaCO}_{3}$ aragonite nanoparticles crystallites depositions on the internal matrix (III, X1000) of each scaffold.

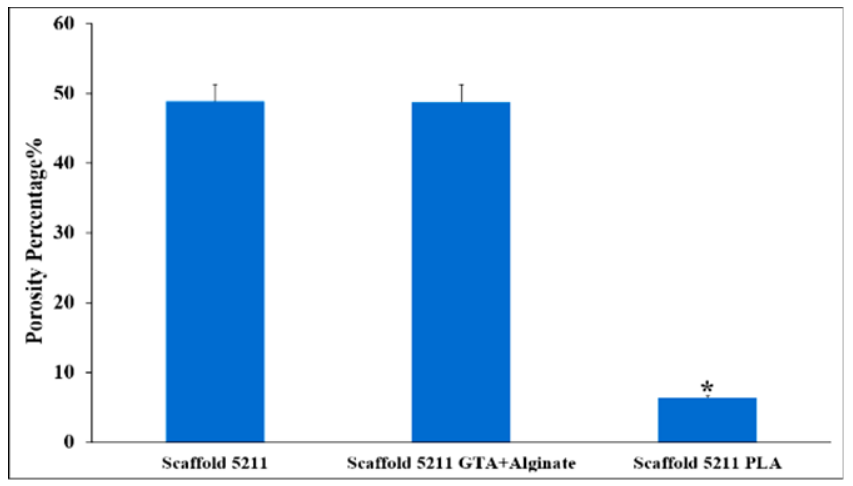

Figure 4: The mean of porosity percentage of three scaffolds tested through liquid displacement method. * Significant difference was observed between the scaffolds at $\mathrm{P}<0.05$.

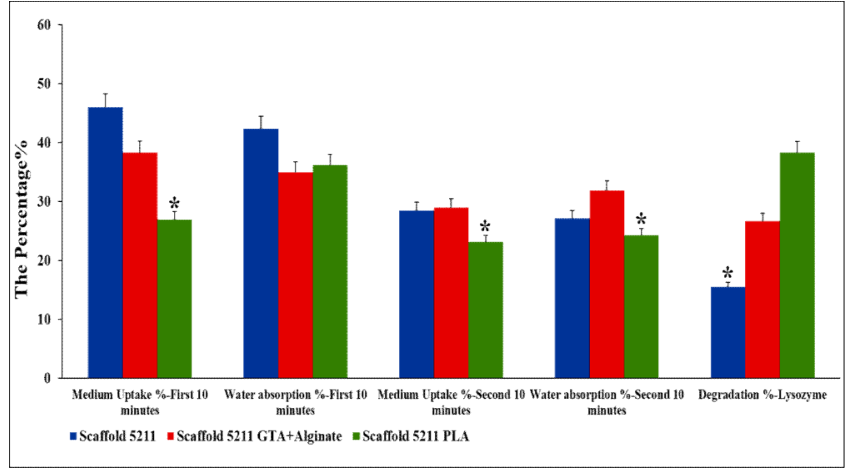

Figure 5: The mean of medium uptake percentage, the mean of water absorption percentage (first and second 10 minutes) and the mean of degradation percentage using Lysozyme. * Significant difference was observed between the three scaffolds at $\mathrm{P}<0.05$. 


\section{Mechanical strength evaluation}

The stiffness and yield were determined from the compression test. Figure 6 shows the compression strength and Young's Modulus of three scaffolds. The compression strengths of S3 was $65.04 \pm 2 \mathrm{MPa}$ and found to be considerably higher compared to the other scaffolds at $(\mathrm{P}<0.05)$. While $\mathrm{S} 1$ displayed the lowest compression strength at $20.31 \pm 4 \mathrm{MPa}$ in spite of a remarkable tendency of increase in the compression strength with the coated scaffolds. The Young's Modulus of S2 was 295.818 \pm 11 $\mathrm{MPa}$ and found to be higher compared to the other scaffolds. While S3 displayed the lowest Young's Modulus at $165.68 \pm 19 \mathrm{MPa}$. Scaffolds from different compositions showed significant differences in the compression strength and Young's Modulus at $(\mathrm{P}<0.05)$.

Table 2: Summary of degradation period of each scaffold during degradation test

\begin{tabular}{cccc}
\hline Scaffold & $\begin{array}{c}\text { Degradation } \\
\text { using } \\
\text { Lysozyme }\end{array}$ & $\begin{array}{c}\text { Degradation } \\
\text { using } \\
\text { PBS }\end{array}$ & $\begin{array}{c}\text { Degradation } \\
\text { using } \\
\text { DW }\end{array}$ \\
\hline S1 & 10 days & 6 days & 2 weeks \\
S2 & 10 weeks & 16 weeks & 4 weeks \\
S3 & 4 weeks & 2 weeks & 2 weeks \\
\hline
\end{tabular}

Table 3: The mean of $\mathrm{pH}$ during degradation period using PBS 7.4

\begin{tabular}{cccccc}
\hline Scaffold & After 24 hours & After 72 hours & After 168 hours & After 288 hours & After 336 hours \\
\hline S1 & $7.67 \pm 0.2^{\mathrm{b}}$ & $7.16 \pm 0.02$ & $7.13 \pm 0.03$ & $8.53 \pm 0.01^{\mathrm{b}}$ & $9.09 \pm 0.01^{\mathrm{c}}$ \\
S2 & $7.50 \pm 0.01^{\mathrm{a}^{*}}$ & $7.07 \pm 0.02$ & $6.91 \pm 0.04$ & $7.35 \pm 0.1^{\mathrm{a}^{*}}$ & $7.73 \pm 0.04^{\mathrm{a}^{*}}$ \\
S3 & $7.90 \pm 0.02^{\mathrm{c}}$ & $6.92 \pm 0.3$ & $7.59 \pm 0.4$ & $8.34 \pm 0.1^{\mathrm{b}}$ & $8.51 \pm 0.07^{\mathrm{b}}$ \\
\hline
\end{tabular}

$\overline{a, b, c}$ different in superscripts show significant difference at $\mathrm{P}<0.05$.

Table 4: The mean of $\mathrm{pH}$ during degradation period using Lysozyme

\begin{tabular}{cccccc}
\hline Scaffold & After 24 hours & After 72 hours & After 168 hours & After 288 hours & After 336 hours \\
\hline S1 & $7.59 \pm 0.04^{\mathrm{b}}$ & $7.34 \pm 0.1$ & $7.57 \pm 0.1^{\mathrm{b}}$ & $8.79 \pm 0.01^{\mathrm{b}}$ & $8.89 \pm 0.02^{\mathrm{c}}$ \\
S2 & $7.42 \pm 0.01^{\mathrm{a}^{*}}$ & $7.47 \pm 0.2$ & $6.80 \pm 0.1^{\mathrm{a}^{*}}$ & $8.50 \pm 0.01^{\mathrm{a}}$ & $8.76 \pm 0.02^{\mathrm{b}}$ \\
S3 & $7.57 \pm 0.04^{\mathrm{b}}$ & $7.27 \pm 0.2$ & $8.35 \pm 0.03^{\mathrm{c}}$ & $8.48 \pm 0.01^{\mathrm{a}^{*}}$ & $8.61 \pm 0.02^{\mathrm{a}^{*}}$ \\
\hline
\end{tabular}

$\overline{a, b, c}$ different in superscripts show significant difference at $\mathrm{P}<0.05$.

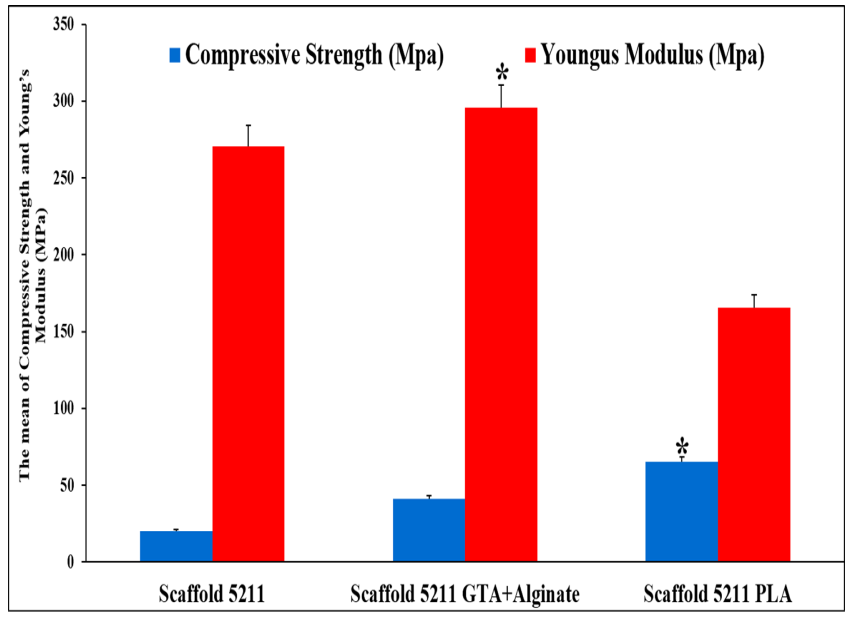

Figure 6: The mean of compressive strength (MPa) and Young's Modulus (Mpa). *Significant difference was observed between the three scaffolds at $\mathrm{P}<0.05$.

\section{Fourier Transform InfraRed (FTIR) analysis}

The FTIR spectra of the scaffolds are represented in Figure 7. In the entire scaffolds, a comparable pattern of spectra was witnessed with minor different in scaffolds were coated. The bands signify some key groups signifying the elongation of hydroxyl, carboxyl, amide, amine and aromatic bands. The occurrence of $\mathrm{N}-\mathrm{H}, \mathrm{C}-\mathrm{N}, \mathrm{C}=\mathrm{C}, \mathrm{C}-\mathrm{H}$, $\mathrm{C}-\mathrm{O}, \mathrm{C}=\mathrm{O}$ and $\mathrm{O}-\mathrm{H}$ groups of the gelatin, dextran, dextrin, GTA, alginate, PLA and aragonite bands of CCAN are also stated. Wave number of 3288-3030, 2926-2918 and 1657$1642 \mathrm{~cm}-1$ were allocated to $\mathrm{N}-\mathrm{H}, \mathrm{C}-\mathrm{H}$ and $\mathrm{C}=\mathrm{O}$ extension vibrations, correspondingly. Additionally, the highest absorption was seen at $1481-1460 \mathrm{~cm}^{-1}$ which was attributed to $\mathrm{C}-\mathrm{H}$ bending vibration initiated from methylene group, whereas $1239 \mathrm{~cm}^{-1}$ was related with C-N elongating vibration. In conclusion, 857-854 and 567-516 $\mathrm{cm}^{-1}$ were equivalent to the vibrations transpired as a result of $\mathrm{C}-\mathrm{C}$ ring and $\mathrm{C}-\mathrm{N}$ bending.

\section{Powder X-Ray Diffraction (PXRD) analysis}

Crystallinity stages were resolute with diffraction angles from $20-70^{\circ}$ at $37^{\circ} \mathrm{C}$. The PXRD configuration of the prepared scaffolds is shown in Figure 8 that informed the PXRD absorption peaks in the scaffold's powders matched each other. This shows that the crystalline excellence of aragonite $\mathrm{CaCO}_{3}$ nanoparticles in these powders is 
sustained during the scaffolds production procedure. PXRD absorption peaks in the CCAN matched each other. Three prominent peaks were found each in CCAN spectra. The first sets of heights were within $2 \theta=26.2^{\circ}$ to $26.5^{\circ}$ while the second set were within $2 \theta=33.2^{\circ}$ to $33.4^{\circ}$ and the third set were within $2 \theta=45.9^{\circ}$ to $46.1^{\circ}$. This shows that the crystalline quality of CCAN is sustained during the course of production. These findings are further supported by PXRD diffractograms indicating presence of aragonite in the entire three samples as equated to a standard calcium carbonate diffractogram having peaks from the shell powders seen to matched closely to the aragonite phase of Joint Committee of Powder Diffraction Society (JCPDS) file no. 00-041-1475. The PXRD investigation done showed essential information on mineral phase of the materials existing in the scaffolds. The obtained evidence from the spectrums established the existence of the distinctive peaks of aragonite. The powder x-ray diffraction (PXRD) and transmission electron microscopy (TEM) methods were used to investigate the phase configuration, the morphology and size of made $\mathrm{CaCO}_{3}$ powder. The isolated and ideal high strength diffraction peaks namely, (26.2), (26.4), (26.5), (33.1), (33.3), (33.4), (45.9), (46) and (46.1) were selected for estimating the nanostructure parameters through several models using Scherrer's formula (Table 5).

The PXRD patterns of scaffolds powders are comparable and display numerous diffraction points that could be apportioned to sphere-shaped crystal structure. Furthermore, the diffraction points are distinctly wider signifying that the particles of prepared powder were in nanosize. Powder X-ray diffraction (PXRD) was utilized in limiting the composition and pureness of the produced $\mathrm{CaCO}_{3}$ nanoparticles. The PXRD patterns of scaffolds powders revealed typical peaks having high density between $2 \theta$ of $26^{\circ}$ and $46^{\circ}$.

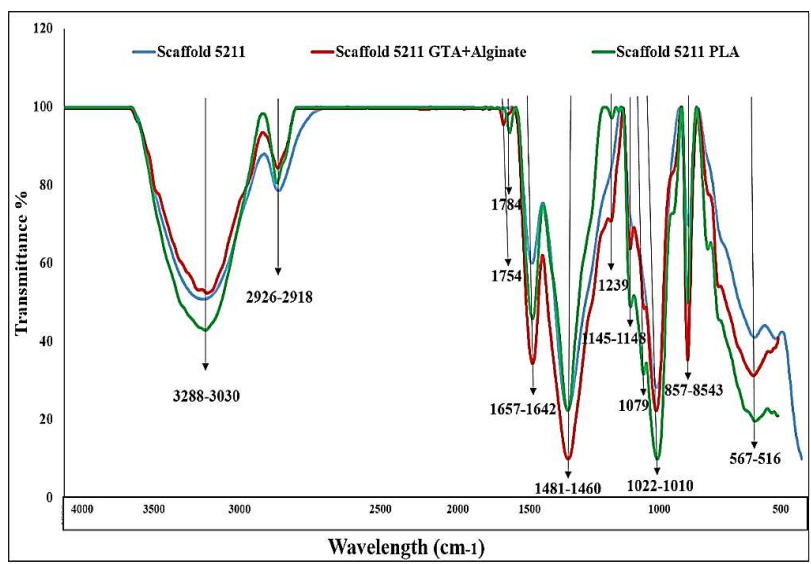

Figure 7: FTIR spectra of scaffolds' powders.

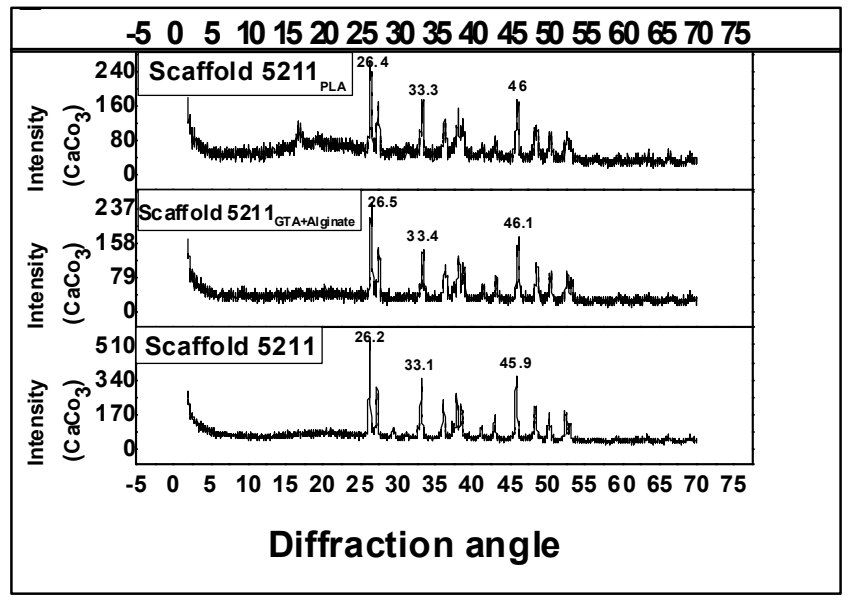

Figure 8: Powder X-Ray Diffraction analysis and the strongest three peaks.

Table 5: Briefing of the structural of $\mathrm{CaCO}_{3}$ at different percentage in the scaffolds composition

\begin{tabular}{|c|c|c|c|c|c|}
\hline Scaffold & $2 \theta \pm 0.001$ & $\mathrm{FWHM} \pm 0.001$ & $\mathrm{~d}(\mathrm{~nm})$ & $\mathrm{D}_{\mathrm{XRD}}(\mathrm{nm})$ & $\mathrm{D}_{\mathrm{TEM}}(\mathrm{nm})$ \\
\hline \multirow{3}{*}{ S1 $(50 \%)$} & 26.2245 & 0.21550 & 33.9549 & 37.9 & \multirow{8}{*}{$\begin{array}{l}\bar{u} \\
\dot{0} \\
+\end{array}$} \\
\hline & 33.1189 & 0.23790 & 27.0271 & 34.8 & \\
\hline & 45.8562 & 0.22290 & 19.7728 & 38.7 & \\
\hline \multirow{3}{*}{ S2 (50\%) } & 26.4575 & 0.28230 & 33.6612 & 28.9 & \\
\hline & 33.3583 & 0.33000 & 26.8386 & 25.1 & \\
\hline & 46.0822 & 0.38220 & 19.6811 & 22.6 & \\
\hline \multirow{3}{*}{ S3 $(50 \%)$} & 26.3653 & 0.32440 & 33.7768 & 25.2 & \\
\hline & 33.2550 & 0.35000 & 26.9196 & 23.7 & \\
\hline & 45.9760 & 0.37600 & 19.7241 & 23 & \\
\hline
\end{tabular}

$2 \theta=$ Two theta, FWHM= Full Width at Half Maximum, $\mathrm{d}=$ crystallite size (nm), $\mathrm{D}_{\mathrm{XRD}}=$ crystallite size (nm) using XRD, $\mathrm{D}_{\mathrm{TEM}}=$ crystallite size $(\mathrm{nm})$ using TEM. 


\section{Differential Scanning Calorimetry (DSC) analysis}

Thermal characteristics of the scaffolds were analyzed using DSC scans as shown in Figure 9. There was no crystallization peak throughout the first run; hence the ratio of crystallinity was determined solitary with the heat of fusion. Firstly, heating rises from room temperature $25^{\circ} \mathrm{C}$ to $250^{\circ} \mathrm{C}$ at $10^{\circ} \mathrm{C} / \mathrm{min}$. throughout this rise, the material shows information on its real physical and morphological condition. This rise was utilized to assess the melting Temperature, $(\mathrm{Tm})$ of the materials. While, the second heating rise was utilized to calculate the glass transition Temperature, $(\mathrm{Tg})$ which is investigative of polymer chain length and hence polymer degradation. The DSC curve for $\mathrm{S} 1$ showed a glass transition point for the non-cross-linked sample at $226^{\circ} \mathrm{C}$ and at $223^{\circ} \mathrm{C}$ for the cross-linked scaffold (S2). The heating of scaffolds results in a loss of the compound structure, and the temperature at which melting procedure occurs was a helpful tool to differentiate these powders preparations, and this transition can be observed by DSC. Endothermal reactions start between $67^{\circ} \mathrm{C}-74^{\circ} \mathrm{C}$, depending on the powders resource, processing and $\mathrm{PH}$. It can be seen that the thermal mark of the powder mix had a minimum melting peak at about $67.16,72.15$ and $73.98^{\circ} \mathrm{C}$ for S2, S3 and S1 correspondingly and the second minimum glass transition peak were between $223^{\circ} \mathrm{C}-226^{\circ} \mathrm{C}$.

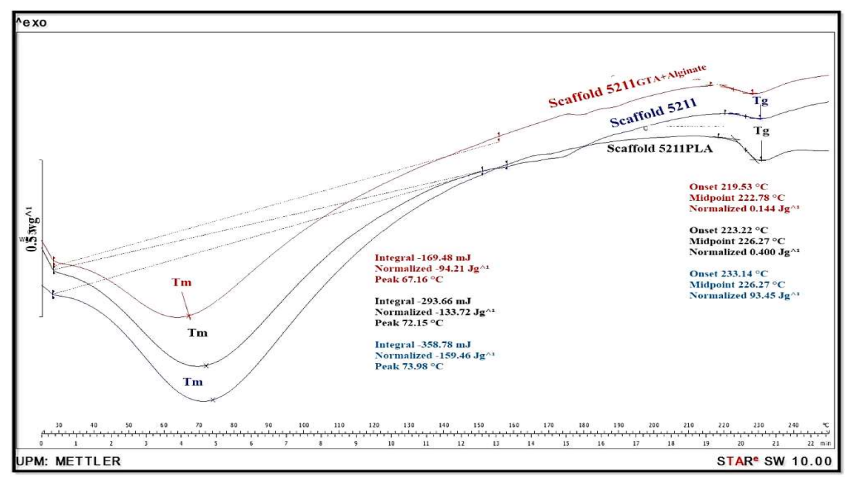

Figure 9: The graphs show the endothermic DSC peak (denaturation) of the coated and non-coated scaffolds' materials (gelatin, dextran, dextrin, GTA, alginate, PLA and CCAN).

\section{MTT (3-(4, 5-dimethyl-2-thiazolyl)-2, 5-}

\section{diphynyltetrazolium bromide) colorimetric assay}

Figure 10 shows the hFOB cells after reactivation; and Figure 11 shows the results of the MTT assay performed on different scaffolds' leachable. The absorbance reading from the assay corresponds to the cell practicality when cultured in the medium containing the leachable of the scaffolds. Cell viability was observed to be higher in the presences of culture medium containing scaffolds leachable compared to normal culture medium (control) that was used as a blank for the experiment. A significantly higher absorbance reading was obtained during 14 days of the culture period for cells grown in the medium containing leachable of coated scaffold (S2) compared to control at $(\mathrm{P}<0.05)$. An increasing trend on cell viability is notable to be relative to the coated framework and type of polymer that used in this framework during 14 days.

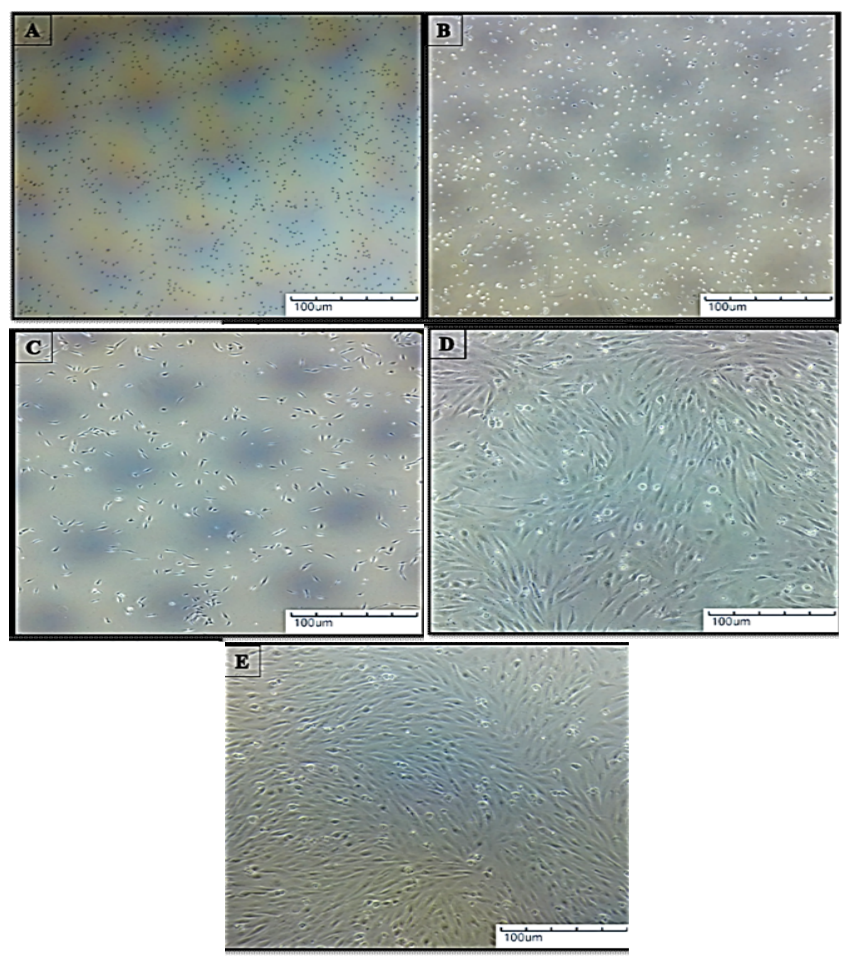

Figure 10: Inverted micrographs of human Fetal OsteoBlast (hFOB) cells, (A) reactivation, (B) 24 hours, (C) 48 hours, (D) 7 days and (E) 10 days of full confluence of cell line culture, (X400).

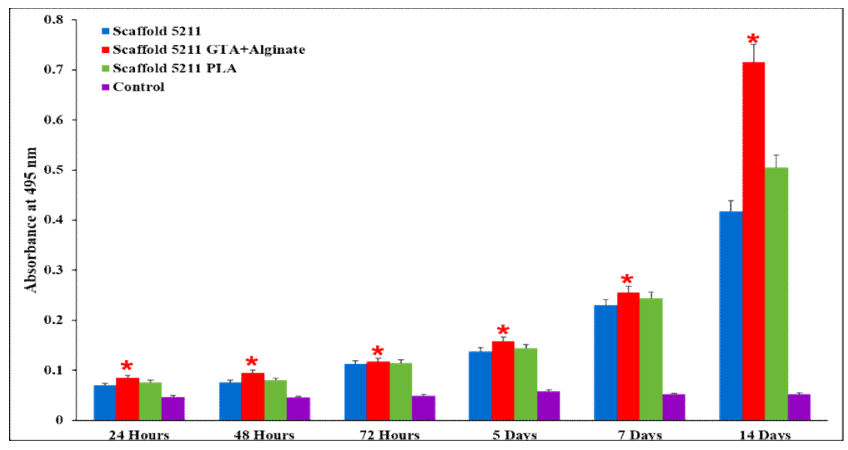

Figure 11: Results of MTT assay on hFOB cells grown in scaffolds S1, S2 and S3 extracts after 24, 48 and 72 hours, 5,7 and 14 days of culture period. * Significant difference was observed from control at $\mathrm{P}<0.05$. 


\section{Alkaline Phosphatase (ALP) analysis}

Figure 12 shows the ALP activity of hFBO cells cultured in medium containing the leachable of scaffolds. The substantial differences in ALP levels were witnessed between the cultures of different scaffold leachable medium within the time frame of the study. However, a significant increasing trend of ALP levels were observed in cells cultured in medium containing leachable of coated scaffold S2 compared to control at $(\mathrm{P}<0.05)$. The cells cultured in medium containing leachable of scaffolds showed an increase in the ALP activities from day 2 to day 7 in medium containing leachable of three scaffolds and decrease in the ALP activities by day 7. A similar trend was also seen for the control group cultured in normal culture medium for the increasing of the ALP activity from day 2 to day 7. A significant increasing trend of ALP levels were observed in cells cultured in medium containing leachable of coated scaffold S2 during first 7 days and in medium containing leachable of non-coated scaffold S1 in day 14. An increasing of ALP level is notable to be relative to use or not use the coated framework and type of polymer that used in this framework during 14 days.

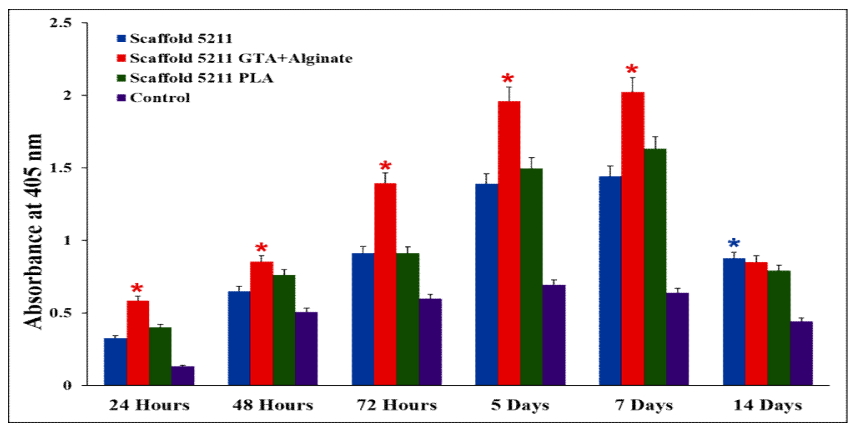

Figure 12: ALP activities of hFOB cells cultured in medium containing the leachable of scaffolds S1, S2 and S3 after 24, 48 and 72 hours, 5, 7 and 14 days of the culture period. * Significant difference was observed from control at $\mathrm{P}<0.05$.

\section{Discussion}

This study aimed at evaluating the gelatin, dextrin, dextran and CCAN, as scaffold materials for bone tissue restoring applications, in addition to improving nanoparticles usage and coated framework in scaffold design. Dextran was selected for this work for the reason of its known resistant to both protein adsorption and cell adhesion. The quantity of dextran used in scaffold is a determinant of its porosity and interconnectivity (19). More so; it is suitable to work with a scaffold that has explicit sites for cell recognition $(35,36)$. In this study lyophilization method produced scaffolds with brilliant porosity (37). Freeze drying method was the main means of evaporation of water in this study which made the mixture concentrated and dense enough to entrap the air bubbles thus, increasing the porosity after the mixture was dried. Similar results were reported by (38-40).

The SEM investigation of the developed scaffolds revealed micro-pores with multiple sizes. The physical structure of this micro-porosity of the scaffolds was mainly attributed to air cavities. These supplied spaces to accommodate the effect of swelling on the scaffolds. This observation was similar to those of $(19,20,39)$. It was observed that the coated scaffolds (S3) have less than 7\% porosity via liquid displacement method using ethanol. Nonetheless, coated (S2) and non-coated (S1) scaffolds showed a relatively higher porosity (Less than 50\%). Similarly, (41-43) reported the similar results. This could be due to the water evaporation during lyophilization process, type of coated copolymer and coated framework. The coated framework controlled the size of pores $(41,42)$.

A vital aspect that is negatively related to porosity is the mechanical characteristics of the scaffold. Porosity of a scaffold undesirably upsets its mechanical strength. Any increase in porosity often occurs as reduction in the mechanical strength of the scaffold. This flaw phenomenon is frequently appearing in polymer-based scaffold and coated framework, as developed in this study. Many studies have reported the enhancement of mechanical characteristics of scaffolds by integration of inorganic biological substances (44-46). Gelatin, dextrin and dextran are known natural polymers that form a fragile hydrogel like scaffolds. The blend of CCAN powder with gelatin, dextrin and dextran resulted in advanced nanocomposite scaffold with tremendously enhanced mechanical characteristics. The results from a study showed a significant rise in equally the mechanical characteristics and Young's Modulus of the scaffold that were combined with CCAN as shown in non-coated scaffold (S1) (27). The results from this study was observed that the mechanical properties (compressive strength and Young's Modulus) of the scaffolds were positively related to the type of coating copolymer and coated framework (scaffold-coating system). This relation was obvious in scaffold S2 and scaffold S3 that showed an increase in their mechanical strength and modulus regardless of scaffold-coating system. This is possibly due to the decreased porosity of scaffolds that have eventually resulted in increasing their mechanical properties.

Spherical pores have good tendency to resist higher compression loads $(47,48)$. Some of the factors that scaffolds must have to control its mechanical properties are pore size and its interconnectivity $(19,20,49)$. In this study, scaffold S2 demonstrated a good mechanical property that ranged between the hard bone structure of $296 \pm 11 \mathrm{Mpa}$ with a compressive strength of $41 \pm 5 \mathrm{MPa}$ creating this combination the most appropriate conditions of mechanical 
properties as earlier reported by $(41,42,50)$ of scaffoldcoating system. Mechanical strength of nanocomposite scaffolds is believed to be added by strong ionic interaction that happens between ions in a compound substance $(20,51,52)$. In this study, the interaction of calcium ions provided by CCAN powder with the carboxyl groups, aldehyde groups and ester groups are possibly the contributing factor. These results were very obvious and interpretable via the FTIR analysis.

The swelling performance of coated and non-coated scaffold improves its pore size $(19,20,47,50,53)$. Swelling ratio of scaffolds is an average below $50 \%$ of medium absorption ability during the first 10 minutes. These results agreed with those of the previous research by (29), who reported that higher swelling rates are positively related to the higher porosity of a scaffold. Nevertheless, (30), reported that swelling ratio was seen to decreased when the scaffold is designed as nanocomposite structure similar to those fabricated in this study, (54), who reported that slowdegrading ceramic or biomineralized surfaces are projected to continue longer after the time when the quantity of the coating is dissolved and no longer efficient, $(53,55)$, reported that the coating on the $\mathrm{Mg}$ scaffold surface prevents the substrate from fast dissolution into the SBF. One probable interpretation for this increase is attributed to the increase surface area of interaction of CCAN with the gelatin, dextrin and dextran networking which enhanced bonding properties of non-coated scaffold. Expectedly, the investigations in this study showed that the swelling rate was significantly decreased with the type of coated copolymer and scaffold-coating system (coated framework). In addition, the porosity ratio was seen to be significantly increased with non-coated scaffolds.

Degradation behavior of the polymer-based scaffolds and a coated scaffold is another essential aspect in the area of tissue engineering. Biodegradability is primarily initiated by polymer and copolymer chain back bone hydrolysis and to a minor extent via enzymatic activity $(56,57)$. Scaffold's weight loss increases from pure to high content during incubation period $(58,59)$. The degradation development displayed by the scaffolds was found to be associated with the coated or non-coated framework and type of copolymer for coating. Studies on the degradation of the scaffolds showed incomparable development as of the swelling ratio. Negative correlation was investigated between the swelling performance and the degradation rate for scaffolds $(19,20,57)$. The non-coated scaffold (S1) showed the lowest degradation rate during both the enzymatic degradation study and the semi-quantitative study $(19,20)$, while coated scaffolds showed the highest degradation rate (57). All the studied scaffolds showed intermediate results being more advantageous for bone tissue engineering applications $(19,20,57-59)$. In this study enzymatic degradation investigation was presented as a short period observation based on the type of lysozyme enzymes. Lysozyme enzymes breaking down the link groups of the gelatin, dextran dextrin, GTA, alginate and PLA network (56). The enzymatic degradation experiment showed that the breakdown of linkages between the scaffolds materials was accelerated as direct result of the raise in fluid uptake. Therefore, the loss of networking structure was initiated in few days of soaking to weeks. There was a positive relationship between the degradation time and the chain scission for coated and non-coated scaffolds that results in decreasing the modulus values $(57,59)$. The structural reliability, constancy and the coated framework led to degradation offset within days up to weeks of the experimental period. Many factors that affect degradation time include polymer crystallinity, scaffold-coating system (coated framework), thermal history, molecular weight, porosity, monomer concentration, the location of the implant and geometry $(56,57)$.

The osteoblast is such a cell that is vulnerable to $\mathrm{pH}$ changes and the acidity of the surrounding environment. In addition, $\mathrm{pH}$ is a significant factor that affects the electrical charges of the incubation solution (60). The degradation of gelatin, dextran and dextrin polymers and GTA cross linked, alginate and PLA copolymers result in decline in $\mathrm{pH}$ values. Such change of $\mathrm{pH}$ has been reported to significantly lower osteoblast activity, ALP activity and collagen synthesis (56). This study theorized that the leaching of CCAN powder from the scaffolds matrices throughout the degradation time results in an increase in the primary $\mathrm{pH}$ value of the solution toward more alkaline environment. Such situation related to the concentration of CCAN powder in the scaffolds as well as GTA cross linked and coated copolymers. This alkalinizing and neutralizing effect of CCAN powder towards the potential acidification (low $\mathrm{pH}$ ) of the solution during degradation creates an ideal mixture for bone grafting functions. Additionally, previous studies have reported a raise in osteoblast activity and fracture healing speed via metabolic alkalosis and/or acidosis $(56,57)$. This explains positive side of the raised $\mathrm{pH}$ of all degrading scaffolds under the study.

In this study, the FTIR spectra analysis of the scaffolds was clear that three scaffolds shown with a comparable configuration of spectra with slightly different in some peaks of coated scaffolds (S2 and S3). This is as a result of the existences of similar substances in variable configuration. The difference may be ascribed to the acuity and wideness of the peaks formed. These changes or differences were found to be related to coated framework and type of coated copolymers. Moreover, the CCAN powder quantity may designate the development of the ionic interaction between the positive charge of calcium ions and the negative charge of the carboxyl group of gelatins, dextrin, dextran, alginate, aldehyde group of GTA and ester group of PLA (19,20,30,61-66). 
The PXRD analysis show vital information on the mineral phase of the components of the scaffolds. The obtained spectra revealed characteristic aragonite peaks. Previous studies by $(20,27,64,66-68)$, also reported the existences of dominant peaks characteristic of aragonite at 26.2 and 46.1 similar to those observed in this study. It appeared that all scaffolds that have CCAN powder also have the aragonite form of calcium carbonate. This aragonite form was presented as the only mineral phase presented in the scaffolds with no impurities or other substance created through the development procedure. On the other hand, the intensity of the peaks well matched CCAN contained in coated scaffolds. Both showed additional intense distinct peaks of aragonite when compared with non-coated scaffolds (S1) that showed broader and vague peaks. The DSC was utilized to investigate the physical conversions or phase transitions of the nanocomposite scaffolds. Melting or glass transition temperatures of the substance were thus determined. The latter, provided an indication of the physical configuration of these scaffolds. The peak found at $67^{\circ} \mathrm{C}-74^{\circ} \mathrm{C}$ was ascribed to gelatin, dextrin, dextran, GTA, alginate and PLA melting. The temperatures are close with those utilized to extrude the mixture. Additionally, there are smaller peaks about $223^{\circ} \mathrm{C}-226^{\circ} \mathrm{C}$ that possibly correlated to glass transition Temperature $(\mathrm{Tg})$. When the temperature raises the sample ultimately reach its melting Temperature (Tm). The outcomes of the DSC of this study were in agreement to those of $(20,27,49,59,62-64,66,69-71)$. Glass transitions Temperature $(\mathrm{Tg})$ may happen as the temperature of an amorphous solid is improved. The transitions came out as a step in the baseline of the recorded DSC indicator.

The established records on the use of human osteoblast cells in testing of cell-biomaterials interactions has been previously given by some authors $(20,72)$. The use of culture medium containing the scaffold leachable was used as a representative of the scaffolds biodegradation model to test the viability and proliferative properties of the cells in the presence of substances leached out from the scaffolds. Findings from a study by $(73,74)$, also showed the release of substances from a nano biocomposite material which could possibly stimulate cells proliferation as indicated by the expression of the ALP biochemical marker for osteoblast cells proliferative activity. The results obtained showed that there is a growing level in cell increasing rate as CCAN powder in the scaffolds composition leaches which correlate with the calcium concentration increase leaching out from the scaffolds as well as the type of coated polymer. Calcium ions leaching out from the scaffolds directly improves the cells propagation rate as a result of calcium ions are well recognized biomolecules that are vital in defining initial cell conduct $(50,75,76)$. A study by $(30)$, concluded that the capability of growing cells in the extracts of a scaffold as being cytocompatible in nature hence supporting the finding of this study in proving the cytocompatible effects of the scaffolds.

There were substantial differences in the ALP levels in the cells cultured in different scaffold extracts; it is worth mentioning that a common trend was observed between the ALP levels with those of the MTT. Increasing levels of ALP directly indicate the presences of a system that is favorable in supporting the cells proliferation rate as well as the subsequent mineralization of the matrices. A study by (77), further supported that the increase in ALP levels which is one of the appearances of three proteins (alkaline phosphatase, collagen and osteopontin) involved in bone remodeling as an indicator of osteoblast cells activity that indirectly increases the concentration of phosphoric acid in addition to supporting matrix mineralization. In this work, the ALP obtained is similar to the results reported by different researchers (78-80). Report shows that ALP is related with calcification with an improved manifestation of this enzyme is outwardly vital earlier than the commencement of matrix mineralization, providing restricted enhancement of inorganic phosphate which is one of the apatite constituents of the mineral phase of bone (81). The ALP activities in this work was shown to be highest within 5 days, the observation is similar to (79), who also stated that the peak ALP expression was observed within 3 days. Nonetheless, the result does not agree with (78) observations who demonstrate that ALP activity improved as the experiment progresses for all samples and particularly after day 14 of incubation. The cells that were cultured on the scaffolds extract reached highest total ALP content at day 5 in the medium containing leachable of three scaffolds which decreased meaningfully on day 14 and reached the peak total ALP content on day 7 in medium containing leachable of scaffold S2 which is similar to the work done by $(78,82-85)$, who reported the unceasing action of the cells in spite of deposition of calcium in the culture.

The decline of ALP may possibly symbolize a reoccurrence to osteoprogenitor cells or maturation to osteocytes, which usually express small amounts of this enzyme. Our result in this study is similar to the result obtained from previous study by $(80,81)$. The ALP activity reduction is related to fast $\mathrm{Ca}^{+2}$ buildup by the matrix vesicles. According to (86) the increase in ALP levels on porous scaffolds is noted as an indication of early cell differentiation followed by a drop that is observable with the initiation of the mineralization process, this further justify the findings from this study. Studies by (87), also reported similar trends in ALP levels that were found to correspond well to the increase and decrease in the levels in regards to the proliferation and growth pattern of the osteoblast cells on the respective scaffold materials. Conclusively, the findings revealed that there is substantial differences $(\mathrm{P}<0.05)$ between scaffolds; this was due to the 
indications that the entire scaffolds configurations have the similar prospective and even quality that can be used in vivo. At days 7 and 14, a drastic increase of ALP and cell proliferation were seen on scaffold S1, S2 and S3 which were cultured under usual conditions; obviously suggest that these scaffolds were accountable for the improved $\mathrm{hFOB}$ cells mineralization.

\section{Conclusion}

This study concluded that using an innovative mixture of calcium carbonate in the form of aragonite cockle shellderived nanoparticles and gelatin, dextrin and dextran is the most appropriate composition that may guarantee the achievement of the developed scaffold purposes in true biological system. This innovative mixture is also essential in achieving the porous structure of the scaffolds which controlled the scaffold-coating system (coated framework) that determined their successive characteristics. The findings showed that three scaffolds were characteristically favorable in terms of its physiochemical evaluation, morphology, mechanical strength as well as biological performance. Furthermore, this study concluded that three scaffolds were excellent biocompatible scaffolds of the third-generation biomaterial-based scaffold category in regards to its in vitro performance. This study also concluded that the MTT and ALP level that was observed in the nanocomposite scaffolds leachable during 14 days of the culture period is significant, clear evidence of its biocompatible composition and porous structural design that is capable of promoting and facilitating cell proliferation was also seen.

\section{Acknowledgements}

The authors thank the Faculty of Veterinary Medicine, Universiti Putra Malaysia, for supporting this study.

\section{References}

1. McMahon RE, Wang L, Skoracki R, Mathur AB. Development of nanomaterials for bone repair and regeneration. J Biomed Mat Res B: Applied Biomat. 2013;101(2):387-397.

2. Parch IPD, Vittorio O, Andreani L, Piolanti N, Cirillo G, Iemma F, Hampel S, Lisanti M. How nanotechnology can really improve the future of orthopedic implants and scaffolds for bone and cartilage defects. J Nanomed Biotherap Discov. 2013;3:2.

3. Oryan A, Alidadi S, Moshiri A, Maffulli N. Bone regenerative medicine: classic options, novel strategies, and future directions. J Orthopae Surg Res. 2014;9:18.

4. Shinoka T. Development of a tissue-engineering vascular graft for use in congenital heart surgery. EBioMed. 2014;1:12-13.

5. Pathak R, Amarpal AHP, Kinjavdekar P, Pawde AM, Rashmi MT, Sharma N, Dhama K. Bone Tissue Engineering: Latest trends and future perspectives. Adv Anim Vet Sci. 2015;3(4):9-22.

6. Huang RL, Kobayashi E, Liu K, Li O. Bone graft prefabrication following the in vivo bioreactor principle. EBioMed. 2016;12:43-54.
7. Sakolish CM, Esch MB, Hickman JJ, Shuler ML, Mahler GJ. Modelling barrier tissues In vitro: Methods, achievements and challenges. EBioMed. 2016;5:30-39.

8. Da Silva VM. Development of new chitosan based biodegradable blends for bone and cartilage tissue engineering [PhD Dissertation]. Minho: Universidade do Minho. 2009.

9. Williams DF. Tissue-Biomaterial Interactions. J Mat Sci. 1987;22:3421-3445

10. Mittal A, Negi P, Garkhal K, Vermas S, Kumar N. Integration of porosity and bio-functionalization to form a $3 \mathrm{D}$ scaffold: cell culture studies and in vitro degradation. Biomed Mat. 2010;5(4):045001.

11. Loh Q, Choong C. Three-dimensional scaffolds for tissue engineering applications: role of porosity and pore size. Tis Eng B. 2013;19(6):485-502.

12. Wang C, Zhao J, Zhao X, Bala H, Wang, Z. Synthesis of nanosized calcium carbonate (aragonite) via a polyacrylamide inducing process. J Powder Tech. 2006;163(3):134-138.

13. Wang Z, Xie G, Wang X, Li G, Zhang Z. Rheology enhancement of polycarbonate/calcium carbonate nanocomposites prepared by meltcompounding. Mat Letters. 2006;60(8):1035-1038.

14. Guo F, Li Y, Xu H, Zhao G, He X. Size-controllable synthesis of calcium carbonate nanoparticles using aqueous foam film as templates. Mat Letters. 2007;61(27):4937-4939.

15. Chen J, Xiang L. Controllable synthesis of calcium carbonate polymorphs at different temperatures. Powder Tech. 2009;189:64-69.

16. Islam KH, Zuki ABZ, Ali ME, Zobir MH, Noordin MM, Loqman MY, Miah G, Wahid H, Hashim U. A novel method for the synthesis of calcium (aragonite) nanoparticles from cockle shells. J Powder Tech. 2013:70-75.

17. Kamba SA, Zakaria ZAB. Osteoblasts growth behavior on bio-based calcium carbonate aragonite nanocrystal. BioMed Res Internat. 2014;2014(Article ID 215097):1-9.

18. Kawaguchi HH, Sakai K, Sera S, Nakajima T, Ebisawa Y, Koyama K. Synthesis of nanosized calcium carbonate (aragonite). Colloid Polymer Sci. 1992:270.

19. Zuki AB, Bahaa FH, Noordin MM. Cockle shell-based biocomposites scaffold for bone tissue engineering. Reg Med Tis Eng: Cells Biomat. 2011:365-390.

20. Bharatham H, Zuki BZ, Perimal EK, Loqman MY, Hamid M. Development and characterization of novel porous 3D alginate-cockle shell powder nanobiocomposite bone scaffold. BioMed Res Internat. 2014;2014(Article ID 146723):1-12.

21. Fleming J, Cornell C, Muschler G. Bone cells and matrices in orthopaedic tissue engineering. Orthopae Clin North America. 2000;31:357-374.

22. Matta C, Khademhosseinic A, Mobasheri A. Mesenchymal stem cells and their potential for microengineering the chondrocyte niche. EBioMed. 2015;2:1560-1561.

23. Vitale-Brovarone C, Verne E, Robiglio L, Appendino P, Bassi F, Martinasso G, Muzio G, Canuto R. Development of glass ceramic scaffolds for bone tissue engineering: Characterization, proliferation of human osteoblasts and nodule formation. Acta Biomat. 2007;3(2):199-208.

24. Takayama Y, Mizumachi K. Effect of lactoferrin-embedded collagen membrane on osteogenic differentiation of human osteoblast-like cells. J Biosci Bioeng. 2009;107:191-195.

25. Nagai Y, Yamazaki C, Ma K, Nozaki T, Toyama K, Yamashita T. Response of osteoblast-like MG63 cells to $\mathrm{TiO}_{2}$ layer prepared by micro-arc oxidation and electric polarization. J Europ Ceramic Soci. 2012;32(11):2647-2652.

26. Zakaria ZAB, Zakaria N, Kasimb Z. Mineral composition of the cockle shell (Anadora granosa) shells, Hard Clamp (Meretrix meretrix) shells and corals (Porites spp): Comparative study. J Anim Vet Adv. 2004;3:445-447.

27. Mahmood SK, Zakaria ZAB, Abdul Razak ISB, Yusof LM, Jaji AZ, Tijani I, Hammadi NI. Preparation and characterization of cockle shell 
aragonite nanocomposite porous 3D scaffolds for bone repair. Biochem Biophys Reports. 2017;10:237-251.

28. Shahini A, Yazdimamaghani M, Walker KJ, Eastman MA, HatamiMarbini H, Smith BJ, Ricci JL, Madihally SV, Vashaee D, Tayebi L. $3 \mathrm{D}$ conductive nanocomposite scaffold for bone tissue engineering. Internat J Nanomed. 2014;9:167-181.

29. Soumya S, Sajesh KM, Jayakumar R, Nair SV, Chennazhi KP. Development of a phytochemical scaffold for bone tissue engineering using Cissus quadrangularis extract. Carbohyd Polymers. 2012;87(2):1787-1795.

30. Peter M, Binulal NS, Soumya S. Nanocomposite scaffolds of bioactive glass ceramic nanoparticles disseminated chitosan matrix for tissue engineering applications. Carbohyd Polymers. 2010;79(2):284289.

31. Han J, Zhou Z, Yin R, Yang D, Nie J. Alginate chitosan/hydroxyapatite polyelectrolyte complex porous scaffolds: Preparation and characterization. Internat $\mathrm{J}$ Bio Macromol. 2010;46(2):199-205.

32. Venkateswarlu K, Sreekanth D, Sandhyarani M, Muthupandi V, Bose AC, Rameshbabu N. X-ray peak profile analysis of nanostructured hydroxyapatite and fluorapatite. Internat J Biosci Biochem Bioinfor. 2012;2(6):389-393.

33. Suryanarayana C, Norton MG. X-Ray Diffraction: A practical approach. New York: Plenum Press Publishing; 1998.

34. Tampieri A, Sandr M, Landi E, Celotti G, Roveri N, MattioliBelmonte M, Virgili L, Gabnana F, Biaaini G. HA/alginate hybrid composites prepared through bio-inspired nucleation. Acta Biomat. 2005; 1:343-351.

35. Le'vesque SG, Lim RM, Shoichet MS. Macroporous interconnected dextran scaffolds of controlled porosity for tissue-engineering applications. Biomat. 2005;26:7436-7446.

36. Vater C, Lode A, Bernhardt A, Reinstorf A, Heinemann C, Gelinsky $\mathrm{M}$. Influence of different modifications of a calcium phosphate bone cement on adhesion, proliferation, and osteogenic differentiation of human bone marrow stromal cells. J Biomed Mat Res A. 2010;92(4):1452-1460

37. Maria MEG. Bone tissue engineering strategy basal on starch scaffolds and bone marrow cells cultured in a flow perfusion bioreactor [PhD Dissertation]. Minho: Universi dade Do Minho Escola De Engenharia. 2004.

38. Kang HG, Kim SY, Lee YM. Novel porous gelatin scaffolds by overrun/particle leaching process for tissue engineering applications. $J$ Biomed Mat Res B: Applied Biomat. 2006;79B:388-397.

39. Dittrich R, Tomandi G, Despang F, Bernhardt A, Hanke Th, Pompe W, Gelinsky M. Scaffolds for hard tissue engineering by ionotropic gelatin of alginate-influence of selected preparation parameters. J American Ceramic Soci. 2007;90(6):1703-1708.

40. Duan B, Wang M. Customized Ca-P/PHBV nanocomposite scaffolds for bone tissue engineering: design, fabrication, surface modification and sustained release of growth factor. J Royal Soci Interface. 2010:115.

41. Kim HW, Knowles JC, Kim HE. Development of hydroxyapatite bone scaffold for controlled drug release via poly (epsilon-caprolactone) and hydroxyapatite hybrid coatings. J Biomed Mat Res. 2004;70B:240-249.

42. Govindan R, Kumar GS, Girija EK. Polymer coated phosphate glass/hydroxyapatite composite scaffolds for bone tissue engineering applications. RSC Adv. 2015;5:60188-60198.

43. Philippart A, Boccaccini AR, Fleck C, Schubert DW, Roether JA. Toughening and functionalization of bioactive ceramic and glass bone scaffolds by biopolymer coating and infiltration: a review of the last 5 years. Expert Rev Med Dev. 2015;12:93-111.

44. Xiao WD, Zhong ZM, Tang YZ, Xu ZX, Xu Z. Repair of critical size bone defects with porous poly (D,L-Iactide)/ nacre nanocomposite hollow scaffold. Saudi Med J. 2012;33(6):601-607.

45. Sagar N, Pandey AK, Gurbani D, Khan K, Singh D, Chaudhari BP, Soni VP, Chattopadyay N, Dhawan A, Bellare JR. In-Vivo efficacy of compliant 3D nano-composite in critical-size bone defect repair: a six month preclinical study in rabbit. Plos One, www.plosone.org. 2013;8(10):e77578.

46. Zhang Y, Wang J, Wang J, Niu X, Liu J, Gao L, Zhai X, Chu K. Preparation of porous PLA/DBM composite biomaterials and experimental research of repair rabbit radius segmental bone defect. Cell Tis Banking. 2015;16(4):615-622.

47. Kolan KCR, Leu MC, Hilmas GE, Comte T. Effect of architecture and porosity on mechanical properties of borate glass scaffolds made by selective laser sintering. Rapid Prototyping J. 2013;65:816-826.

48. Tavangarian F, Emadi R. Preparation of bioactive nanostructure scaffold with improved compressive strength. Ceramics-Silikáty. 2011;55(1):49-53.

49. Haugh MG. The development of novel scaffolds for tissue engineering with a range of structural and mechanical properties $[\mathrm{PhD}$ Dissertation]. Dublin: University of Dublin. 2009.

50. Yazdimamaghani M, Razavi M, Vashaee D, Tayebi L. Development and degradation behavior of magnesium scaffolds coated with poly caprolactone for bone tissue engineering. Mat Letters. 2014;134:106110.

51. Bernhardt A, Lode A, Peters F, Gelinsky M. Novel ceramic bone

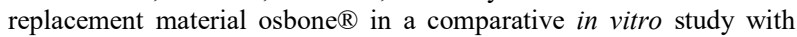
osteoblasts. Clin Oral Implants Res. 2011;22(6):651-657.

52. Gu W, Wu C, Chen J, Xiao Y. Nanotechnology in the targeted drug delivery for bone diseases and bone regeneration. Internat J Nanomed. 2013;8:2305-2317.

53. Virtanen $\mathrm{S}$. Biodegradable $\mathrm{Mg}$ and $\mathrm{Mg}$ alloys: corrosion and biocompatibility. Mat Sci Eng B. 2011;176:1600-1608.

54. Leach JK, Kaigler D, Wang Z, Krebsbach PH, Mooney DJ. Coating of VEGF-releasing scaffolds with bioactive glass for angiogenesis and bone regeneration. Biomat. 2006;27:3249-3255.

55. Kirkland N, Birbilis N, Staiger M. Assessing the corrosion of biodegradable magnesium implants: a critical review of current methodologies and their limitations. Acta Biomat. 2012;8:925-936.

56. Navarro M, Michiardi A, Planell JA. Biomaterials in orthopaedics. J Royal Soci Interface. 2008;5(27):1137-1158.

57. Narayan R. Specialized fabrication processes: rapid prototyping. Biomed Mat. 2009:493-423.

58. Ardakani MH, Kavian F, Moztarzadeh F, Eslaminejad M, Zamanian A, Bagheri F. Poly (lactic-co-glycolic) / nanostructured merwinite porous composites for bone tissue engineering. I. preparation and Morphology. Key Eng Mat. 2012:718-722.

59. Fouad H, Elsarnagawy T, Almajhadi FN, Khalil KA. Preparation and in vitro thermo-mechanical characterization of electrospun PLGA nanofibers for soft and hard tissue replacement. Internat J Electrochem Sci. 2013;8:2293-2204.

60. Wang K, Zhou C, Hong Y, Zhang X. A review of protein adsorption on bioceramics. J Interface Focus. 2012;2(3):259-277.

61. Lee CR, Grodzinsky AJ, Spector M. The effects of crosslinking of collagen-glycosaminoglycan scaffolds on compressive stiffness, chondrocyte-mediated contraction, proliferation and biosynthesis. Biomat. 2001;22:3145-3154.

62. Henton DE, Gruber P, Lunt J, Randall J. Polylactic Acid Technology. 2005; 16:527-578.

63. Avérous L. Polylactic Acid: Synthesis, Properties and Applications. 2008;21:433-435.

64. Mohamed M, Yusup S, Maitra S. Decomposition study of calcium carbonate in cockle shell. J Eng Sci Tech. 2012;7(1):1-10.

65. Hoque ME, Shehryar M, Islam KMN. Processing and characterization of cockle shell calcium carbonate $\left(\mathrm{CaCO}_{3}\right)$ bioceramic for potential application in bone tissue engineering. J Mat Sci Eng. 2013;2(4):1-5.

66. Bharatham H, Zuki BZ, Perimal EK, Loqman MY, Hamid M. Mineral and physiochemical evaluation of cockle shell (Anadara granosa) and other selected molluscan shell as potential biomaterials. Sains Malaysiana. 2014;43(7):1023-1029.

67. Mass T, Drake JL, Haramaty L, Rosenthal Y, Schofield OME, Sherrell RM, Falkowski PG. Aragonite Precipitation by "Proto- 
Polyps " in Coral Cell Cultures. Plos One. www.plosone.org. 2012;7(4):e35049.

68. Moseke C, Gelinsky M, Groll J, Gbureck U. Chemical characterization of hydroxyapatite obtained by wet chemistry in the presence of V, Co, and Cu ions. J Mat Sci Eng C. 2013;33(3):16541661.

69. Lee S, Kim SH, Han Y, Kim Y. Synthesis and degradation of endgroup functionalized polylactide. J Polymer Sci A: Polymer Chem. 2001;39:973.

70. Marcos M, da Paula S, Fabiana BB, Medeiros R, Adriano MB, M'arcio AF, El'1dio A. Characterization of aluminized polyethylene blends via mechanical recycling. Mat Sci Eng A. 2005;403:37-41.

71. Thumsorn S, Yamada K, Leong YW, Hamada H. Development of cockle shell-derived $\mathrm{Caco}_{3}$ for flame retardancy of recycled PET/recycled PP blends. Mat Sci Applications. 2011;2:59-69.

72. Trentz OA, Hoerstrup SP, Sun LK, Bestmann L, Platz A, Trentz OL. Osteoblasts response to allogenic and xenogenic solvent dehydrated cancellous bone in vitro. Biomat. 2003;24(20):3417-3426.

73. Kim H, Lee JH, Suh H. Interaction of Mesenchymal stem cells and osteoblasts for in vitro osteogenesis. Yonsei Med J. 2003;44:187-197.

74. Kim HW, Kim HE, Salih V. Stimulation of osteoblast responses to biomimetic nanocomposites of gelatin-hydroxyapatite for tissue engineering scaffolds. Biomat. 2005;26(25):5221-5230.

75. Navarro M, Ginebra MP, Planell JA, Zeppetelli S, Ambrosio L. Development and cell response of a new biodegradable composite scaffold for guided bone regeneration. J Mat Sci: Mat Med. 2004;15(4):419-422.

76. Borsari V, Giavaresi G, Fini M, Torricelli P, Salito A, Chiesa R, Chiusoli L, Volpert A, Rimondini L, Giardino R. Physical characterization of different roughness titanium surfaces, with and without hydroxyapatite coating, and their effect on human osteoblastlike cells. J Biomed Mat Res B: Applied Biomat. 2005;75(2):359-368.

77. Guo X, Yan S, Shi B, Feng Y. Effect of excessive vitamin A on alkaline phosphatase activity and concentrations of calcium-binding protein and bone Gla-protein in culture medium and CaBP mRNA expression in osteoblasts of Broiler Chickens. Asian Australian J Anim Sci. 2011;24(2):239.
78. Kose GT, Korkusuz F, Korkusuz P, Purali N, Özkul A, Hasirci V. Bone generation on PHBV matrices: an in vitro study. Biomat. 2003;24:4999-5007.

79. Park EK, Lee YE, Je-Yong C, Sun-Ho O, Hong-In S, Kyo-Han K, Kim KS, Shin-Yoon KS. Cellular biocompatibility and stimulatory effects of calcium metaphosphate on osteoblastic differentiation of human bone marrow-derived stromal cells. J Biomat. 2004;25:34033411 .

80. Wang Y, Zhang S, Zeng X, Ma LL, Weng W, Yan W, Qian M. Osteoblastic cell response on fluoridated hydroxyapatite coatings. Acta Biomat. 2007;3(2):191-197.

81. Genge BR, Sauer GR, Wu LN, Mc Lean FM, Wuthier RE. Correlation between loss of alkaline phosphatase activity and accumulation of calcium during matrix vesicle-mediated mineralization. J Bio Chem. 1988;263:18513-18519.

82. Li Z, Ramay HR, Hauch KD, Xia D, Zhang M. Chitosan-alginate hybrid scaffolds for bone tissue engineering. Biomat. 2005;26:39193928.

83. Jiang $\mathrm{T}$, Abdel-Fattah WI, Laurencin CT. In vitro evaluation of chitosan/poly (Lactic acid-glycolic acid) sintered microsphere scaffolds for bone tissue engineering. Biomat. 2006;27(28):48944803.

84. Rani VVD, Ramachandran R, Chennazhi KP, Tamura H, Nair SV, Jayakumar R. Fabrication of alginate/nanoTiO ${ }_{2}$ needle composite scaffolds for tissue engineering applications. Carbohyd Polymers. 2011;83(2):858-864.

85. Metze AL, Grimm A, Nooeaid P, Roether JA, Hum J, Newby PJ, Schubert DW, Boccaccini AR. Gelatin coated $45 \mathrm{~S} 5$ bioglass ${ }^{\circledR}$ derived scaffolds for bone tissue engineering. Key Eng Mat. 2013;541:31-39.

86. Ehara A, Ogata $\mathrm{K}$, Imazato S, Ebisu S, Nakano T, Umakoshi Y. Effects of a-TCP and TetCP on MC3T3-E1 proliferation, differentiation and mineralization. Biomat. 2003;24(5):831-836.

87. St-Pierre JP, Gauthier M, Lefebvre LP, Tabrizian M. Threedimensional growth of differentiating MC3T3-E1 pre-osteoblasts on porous titanium scaffolds. Biomat. 2005;26(35):7319-7328. 